\title{
FONTES E DOSES DE SÓDIO NO CRESCIMENTO E NA CONCENTRAÇÃO DE NUTRIENTES EM CULTIVARES DE CANA-DE-AÇÚCAR (Sacharum spp)
}

\author{
HEROLDO WEBER
}

Orientador: Prof. Dr. JOSÉ RENATO SARRUGE

Tese apresentada à Escola Superior de Agricultura "Luiz de Queiroz", da Universidade de São Paulo, para obtenção do título de Doutor em Agronomia. Área de Concentração: Solos e Nutrição de Plantas.

PIR A CICABA

Estado de São Paulo - Brasil

Outubro, 1983 
ii.

$\AA$ Rosalba, Flāvia e Betina Aos meus pais 


\section{AGRADECIMENTOS}

Ao Prof. Dr. Josē Renato Sarruge.

Ao Prof. Dr. Antonio Roque Dechen.

Ao Engo Agro Demetrio Ferreira de Azeredo.

Ao Engo Agro Dr. Josē Orlando Filho.

A Enga Agrà Joana Rita Vieira.

Ao Paulo Roberto Gomes Barreto.

Aos funcionārios do Setor de Nutrição Mineral de Plantas, do Departamento de Química da Escola Superior de Agricultura "Iuiz de Queiroz".

A Escola Superior de Agricultura "Iuiz de Queiroz", Universidade de são Paulo.

Ao Planalsucar. 
INDICE

Pāgina

RESUMO

SUMMARY

1 . INTRODUÇÃO

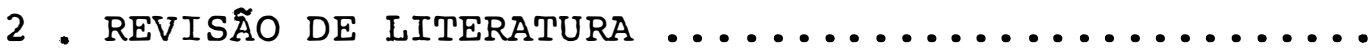

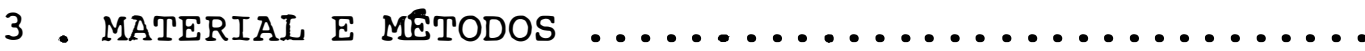

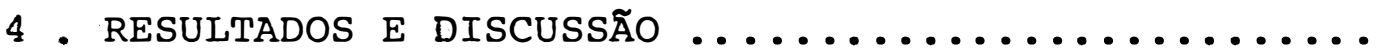

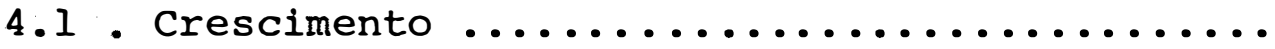

4.2 . Nitrogênio $\ldots \ldots \ldots \ldots \ldots \ldots \ldots \ldots \ldots \ldots$

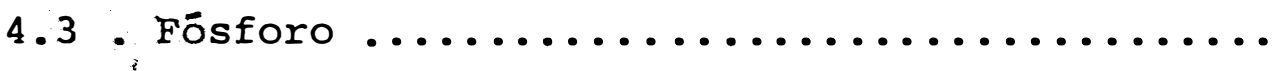

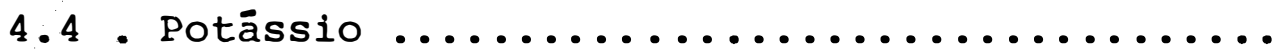

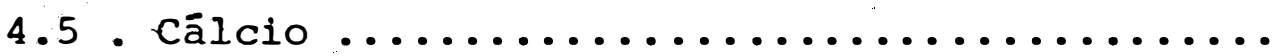

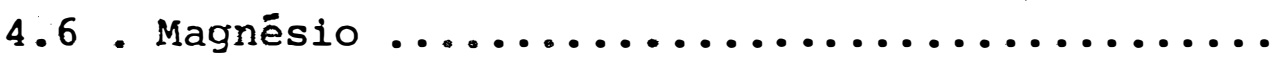

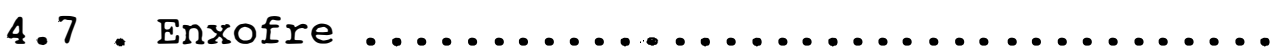

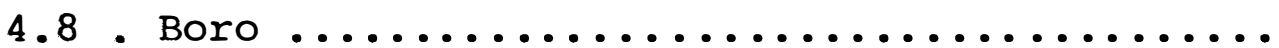

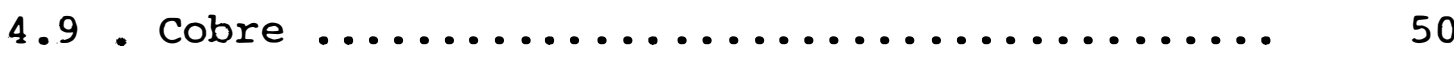

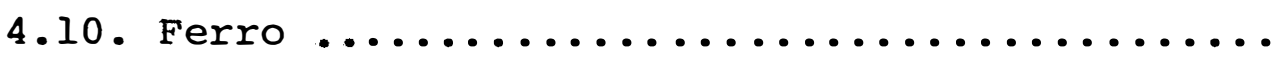

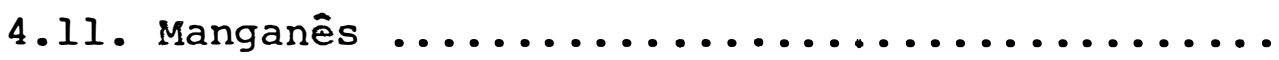

4.12 . Zinco $\ldots \ldots \ldots \ldots \ldots \ldots \ldots \ldots \ldots \ldots \ldots \ldots \ldots \ldots \ldots$

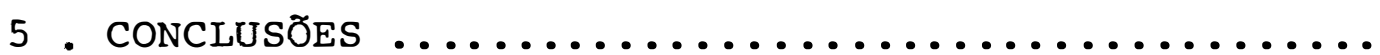

6 . Literatura citada $\ldots \ldots \ldots \ldots \ldots \ldots \ldots \ldots \ldots$ 
LISTA DE TABELAS

Pāgina

1 - Peso de matēria seca (mg/planta) das partes das plantas em função dos tratamentos (média de 4 re petições) $\quad \ldots \ldots \ldots \ldots \ldots \ldots \ldots \ldots \ldots \ldots \ldots \ldots$

2 - Resumo da anālise de variância dos valores de pe so de matēria seca de raízes, colmos e folhas, das cultivares de cana-de-açūcar, em função da fonte e dose de sódio na solução nutritiva ......

3 . Equações de regressão dos valores de peso de matéria seca de raizes, colmos e folhas de cultivares de cana-de-açúcar, obtidas em função da fonte e dose de sódio, e o coeficiente de deter

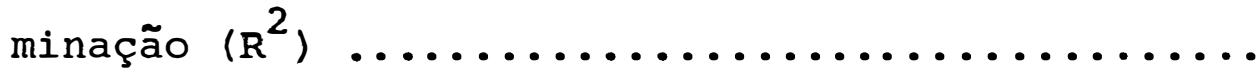

4 . Concentração de nitrogênio $(z)$ nas folhas das diferentes cultivares de cana-de-açúcar, em fun

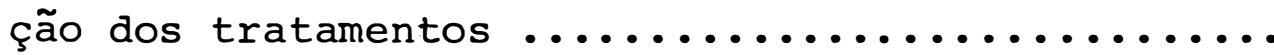

5 . Resumo da anālise de variância das concentrações (8) de nitrogênio, fósforo, potássio, cālcio, ma gnésio e enxofre nas folhas, em função da fonte e dose de sōdio 
6 . Equações de regressão dos teores de nitrogênio (y) nas folhas das cinco cultivares utilizadas, em função das fontes e doses de sōdio (x) na sọ

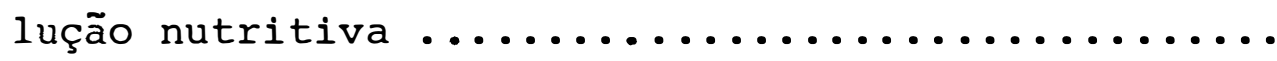

7 . Concentração de fósforo (\%) nas folhas das dife rentes cultivares de cana-de-açūcar, em função

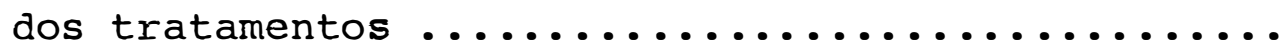

8 . Equações de regressão dos teores de fōsforo (y) nas folhas das cinco cultivares utilizadas, em função das fontes e doses de sódio $(x)$ na solu

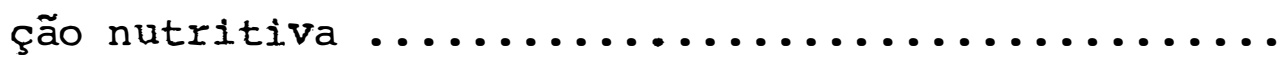

9 . Concentração de potássio (q) nas folhas das diferentes cultivares de cana-de-açúcar, em fun-

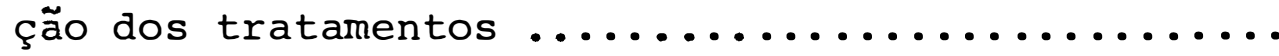

10. Equações de regressão dos teores de potássio (y) nas folhas das cinco cultivares utilizadas, em função das fontes e doses de sódio (x) na solu-

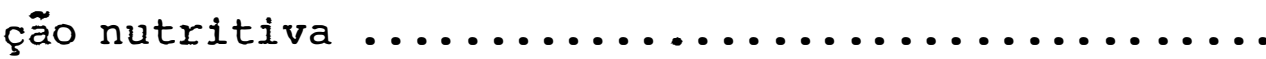

11. Concentração de cālcio (q) nas folhas das diferentes cultivares de cana-de-açūcar, em função dos tratamentos $\ldots \ldots \ldots \ldots \ldots \ldots \ldots \ldots \ldots \ldots \ldots$ 
12. Equações de regressão dos teores de cálcio (y) nas folhas das cinco cultivares utilizadas, em função das fontes e doses de sōdio (x) na solu-

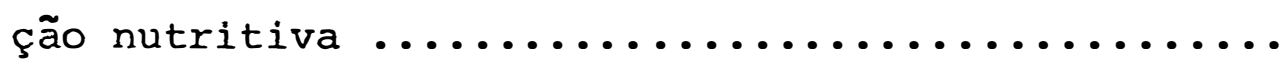

13. Concentração de magnésio (q) nas folhas das diferentes cultivares de cana-de-açūcar, em fun-

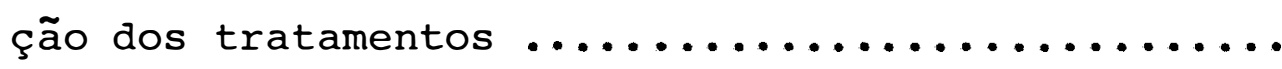

14. Equações de regressão dos teores de magnésio $(y)$ nas folhas das cinco cultivares utilizadas, em função das fontes e doses de sódio ( $x$ ) na solução nutritiva $\ldots \ldots \ldots \ldots \ldots \ldots \ldots \ldots \ldots \ldots \ldots \ldots$

15. Concentração de enxofre ( 8 ) nas folhas das difę rentes cultivares de cana-de-açūcar, em função

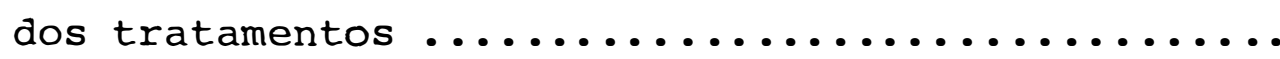

16. Equações de regressão dos teores de enxofre (y) nas folhas das cinco cultivares utilizadas, em função das fontes e doses de sōdio $(x)$ na solu-

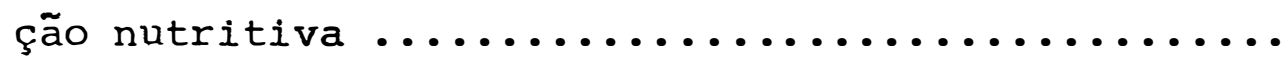

17. Concentração de boro (ppm) nas folhas das diferentes cultivares de cana-de-açūcar, em função

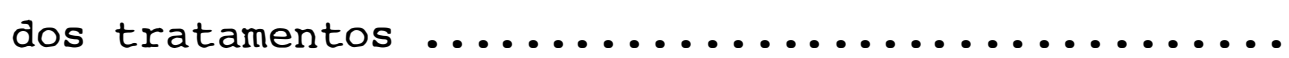


18. Resumo da anālise de variância das concentra ções (ppm) de boro, ferro, manganês e zinco nas folhas, em função da fonte e dose de sōdio na so

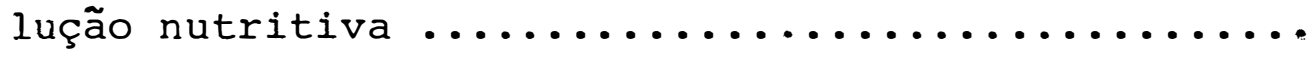

19. Equações de regressão dos teores de boro (y) nas folhas das cinco cultivares utilizadas, em função das fontes e doses de sōdio (x) na solução

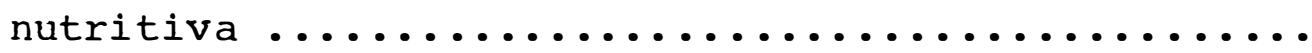

20. Concentração de cobre (ppm) nas folhas das dife rentes cultivares de cana-de-açūcar, em função das doses de $\mathrm{Na}_{2} \mathrm{SO}_{4} \ldots \ldots \ldots \ldots \ldots \ldots \ldots \ldots \ldots . \ldots . \ldots$

21. Resumo da anälise de variância das concentrações (ppm) de cobre, em função das doses de $\mathrm{Na}_{2} \mathrm{SO}_{4} \ldots \ldots$.

22. Equações de regressão dos teores de cobre (y) nas folhas das cinco cultivares utilizadas, em função das doses de sulfato de sódio $(x)$ na solução

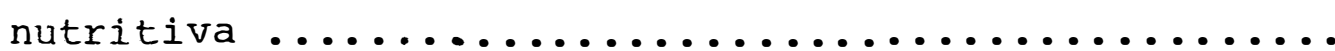

23. Concentração de ferro (ppm) nas folhas das dife rentes cultivares de cana-de-açūcar, em função dos tratamentos $\ldots \ldots \ldots \ldots \ldots \ldots \ldots \ldots \ldots \ldots \ldots$ 
24. Equações de regressão dos teores de ferro(y) nas folhas das cinco cultivares utilizadas, em função das fontes e doses de sódio ( $x$ ) na solução

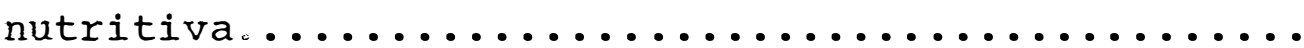

25. Concentração de manganès (ppm) nas folhas das di ferentes cultivares de cana-de-açūcar, em fun-

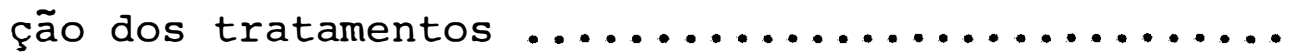

26. Equações de regressão dos teores de manganès (y) nas folhas das cinco cultivares utilizadas, em função das fontes e doses de sódio (x) na solu-

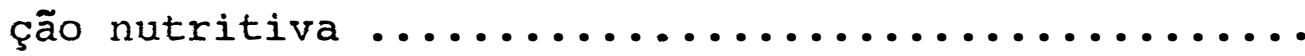

27. Concentração de zinco (ppm) nas folhas das diferentes cultivares de cana-de-açūcar, em função dos tratamentos $\ldots \ldots \ldots \ldots \ldots \ldots \ldots \ldots \ldots \ldots$

28. Equações de regressão dos teores de zinco (y) nas folhas das cinco cultivares utilizadas, em funçao das fontes e doses de sódio (x) na solução nutritiva ..... 
FONTES E DOSES DE SÓDIO NO CRESCIMENTO E NA CONCENTRAÇ̃̃O DE NUTRIENTES EM CULTIVARES DE CANA-DE-ACUCAR. (Saccharum spp)

Candidato: Heroldo Weber

Orientador: Prof. Dr. José Renato Sarruge

RESUMO

Mudas de cana-de-açūcar (Saccharum ssp), das cul tivares $C B 45-3, \mathrm{RB} 70194, \mathrm{RB} 725828, \mathrm{NA56-79}$ e CP51-22, foram transplantadas para recipientes contendo solução nutritiva (15 litros), recebendo doses de 0,69, 138, 207. e 276ppm de só dio, fornecido na forma de sulfato e cloreto, com os objetivos dé (a) verificar a influência de fontes de sódio no crescimento inicial das cultivares, através da produçăo de matēria seca; (b) determinar o efeito dos sais de sódio $\left(\mathrm{Na}_{2} \mathrm{SO}_{4}\right.$ e $\mathrm{NaCl})$ sobre a concentração de nutrientes nas folhas, e, (c) observar diferenças no comportamento das cultivares. Oitenta dias após o transplante, as plantas foram coletadas e separadas em: ralzes, colmos + bainhas e folhas. Determinaram-se as produçōes de matēria seca das partes e as concentrações de macro e micronutrientes, nas folhas, ex ceto $\mathrm{Cl}$ e Mo.

Foram obtidas equaçōes de regressão, atravēs de 
dados calculados, de produção de matēria seca de raízes, colmos + bainhas e lâminas, e das concentrações de nutrientes nas folhas, em função da fonte e dose de sódio.

Os resultados mostram que:

- Ambas as formas, sulfato de sōdio e cloreto de sōdio, foram prejudiciais para o crescimento inicial das cultivares de cana-de-açūcar: CB45-3, RB70194, RB725828, NA56-79 e CP51-22, evidenciando o efeito tóxico do ion específico, sō dio.

- As cultivares apresentaram, entre si, comportamento diferenciado.

- Não foi possível avaliar de maneira genērica os efeitos das fontes de sōdio, uma vez que, os mesmos foram produtos de interações com dosagens e cultivares.

- o sulfato de sódio apresentou, em determinadas faixas de concentrações e cultivares, efeitos benēficos sobre a produção de matēria seca e a concentração de nutrientes.

- Independente da forma, sulfato ou cloreto, te ores de sōdio, na solução, superiores a 200ppm, em mëdia, afe taram negativamente a acumulação de matēria seca das ralzes, colmos e folhas.

- Os sais, sulfato e cloreto de sódio, provocaram nos teores de macro e micronutrientes nas folhas das cul- 
tivares efeitos predominantes no sentido de:

\begin{tabular}{|c|c|c|c|c|}
\hline Cultivar. & $\mathrm{Na}_{2} \mathrm{SO}_{4}$ & $\mathrm{NaCl}$ & $\mathrm{Na}_{2} \mathrm{SO}_{4}$ & $\mathrm{NaCl}$ \\
\hline & Acréscimos & nos teores & Decréscimos & nos teores \\
\hline CB 45-3 & $\mathrm{K}, \mathrm{Ca}, \mathrm{Mg}, \mathrm{Fe}, \mathrm{Mn}, \mathrm{Zn}$ & $\mathrm{K}, \mathrm{Mg}, \mathrm{B}, \mathrm{Mn}, \mathrm{Zn}$ & $\mathrm{P}$ & $\mathrm{N}, \mathrm{P}, \mathrm{Ca}, \mathrm{S}$ \\
\hline RB70194 & $N, P$ & $\mathrm{P}, \mathrm{K}, \mathrm{B}, \mathrm{Fe}, \mathrm{Mn}, \mathrm{Zn}$ & $\mathrm{K}, \mathrm{Ca}, \mathrm{Mg}, \mathrm{Fe}, \mathrm{Mn}, \mathrm{Zn}$ & $\mathrm{Mg}, \mathrm{S}$ \\
\hline RB725828 & $\mathrm{N}, \mathrm{K}, \mathrm{Ca}, \mathrm{Mg}$ & $\mathrm{P}, \mathrm{K}, \mathrm{Mg}, \mathrm{B}, \mathrm{Fe}, \mathrm{Mn}, \mathrm{Zn}$ & $\mathrm{P}, \mathrm{Mn}$ & $\mathrm{N}, \mathrm{S}$ \\
\hline NA56-79 & Mn & $\mathrm{P}, \mathrm{Mg}, \mathrm{B}, \mathrm{Mn}$ & $\mathrm{P}, \mathrm{K}, \mathrm{Ca}, \mathrm{Fe}, \mathrm{Zn}$ & $\mathrm{N}, \mathrm{Ca}, \mathrm{S}$ \\
\hline CP51-22 & $\mathrm{N}, \mathrm{Fe}, \mathrm{Mn}, \mathrm{Zn}$ & $\mathrm{P}, \mathrm{B}, \mathrm{Mn}^{\circ}$ & $\mathrm{P}, \mathrm{Ca}$ & $\mathrm{N}, \mathrm{Ca}, \mathrm{Mg}, \mathrm{S}$ \\
\hline
\end{tabular}


SOURCES AND DOSAGES OF SODIUM IN SUGARCANE (Saccharum spp) GROWTH AND IN NUTRIENT CONCENTRATION.

Author: Heroldo Weber

Adviser: Prof. Dr. José Renato Sarruge

SUMMARY

Sugarcane (Saccharum ssp) cuttings of cultivars CB45-3, RB70194, RB725828, NA56-79 and CP51-22 were transplanted to recipients containing nutritive solution liters) to which $0,69,138,207$, and $276 \mathrm{ppm}$ sodium (in the form of sulphate and chloride) were added. The objectives of this trial were: (a) to assess the influence of sodium sources on the initial growth of each cultivar, through production of dry matter; (b) to determine the effect of sodium salts $\left(\mathrm{NA}_{2} \mathrm{SO}_{4}\right.$ and $\left.\mathrm{NaCl}\right)$ on nutrient concentration in leaves; and, (c) to observe differences in behavior of the cultivars.

Eighty days after transplant, the plants were collected and separated into: roots, stalks + sheaths, and leaves (blades). Dry matter production of the various parts and macro- and micro- nutrients (except chloride and molibedenium) concentrations in leaves were determined.

Regression equations were obtained through data calculated on dry matter production from roots, stalks + 
sheaths, and leaves, as a function of sodium source and dosage.

The results show that:

- Both forms - sodium sulphate and chloride impaired the initial growth of sugarcane cuItivars CB45-3, RB70194, RB725828, NA56-79 and CP51-22, showing the toxic effect of the specific ion, sodium.

- The various cultivars exhibited different behaviors.

- It was not possible to make an overall assessment of the effect of sodium sources, since these were products of dosage and cultivar interactions.

- For certain concentration ranges and cultivars, sodium sulphate brought about beneficial effects on dry matter production and nutrient concentration.

- Sodium contents (regardless of the form, sulphate or chloride) above an average of $200 \mathrm{ppm}$ in the solution exerted a negative effect on dry matter accumulation in roots, stalks and leaves.

- The salts - sodium sulphate and chloride exerted the following predominant effects on macro- and micro- 
nutrient content in cultivar leaves:

\begin{tabular}{|c|c|c|c|c|}
\hline Cultivar & $\mathrm{Na}_{2} \mathrm{SO}_{4}$ & $\mathrm{NaCl}$ & $\mathrm{Na}_{2} \mathrm{SO}_{4}$ & $\mathrm{NaCl}$ \\
\hline & Increases in & contents & Decreases in & contents \\
\hline $\mathrm{CB} 45-3$ & $\mathrm{~K}, \mathrm{Ca}, \mathrm{Mg}, \mathrm{Fe}, \mathrm{Mn}, \mathrm{Zn}$ & $\mathrm{K}, \mathrm{Mg}, \mathrm{B}, \mathrm{Mn}, \mathrm{Zn}$ & $\mathrm{P}$ & $\mathrm{N}, \mathrm{P}, \mathrm{Ca}, \mathrm{S}$ \\
\hline $\mathrm{RB} 70194$ & $\mathrm{~N}, \mathrm{P}$ & $\mathrm{P}, \mathrm{K}, \mathrm{B}, \mathrm{Fe}, \mathrm{Mn}, \mathrm{Zn}$ & $\mathrm{K}, \mathrm{Ca}, \mathrm{Mg}, \mathrm{Fe}, \mathrm{Mn}, \mathrm{Zn}$ & $\mathrm{Mg}, \mathrm{S}$ \\
\hline RB725828 & $\mathrm{N}, \mathrm{K}, \mathrm{Ca}, \mathrm{Mg}$ & $\mathrm{P}, \mathrm{K}, \mathrm{Mg}, \mathrm{B}, \mathrm{Fe}, \mathrm{Mn}, \mathrm{Zn}$ & $\mathrm{P}, \mathrm{Mn}$ & $\mathrm{N}, \mathrm{S}$ \\
\hline NA56-79 & Mn & $\mathrm{P}, \mathrm{Mg}, \mathrm{B}, \mathrm{Mn}$ & $\mathrm{P}, \mathrm{K}, \mathrm{Ca}, \mathrm{Fe}, \mathrm{Zn}$ & $\mathrm{N}, \mathrm{Ca}, \mathrm{S}$ \\
\hline CP51-22 & $\mathrm{N}, \mathrm{Fe}, \mathrm{Mn}, \mathrm{Zn}$ & $P, B, M n$ & $\mathrm{P}, \mathrm{Ca}$ & $\mathrm{N}, \mathrm{Ca}, \mathrm{Mg}, \mathrm{S}$ \\
\hline
\end{tabular}


1. INTRODUŞก̃O:

A vasta extensão do territōrio brasileiro, juntamente com a tradição do cultivo da cana-de-açūcar e atualmente a crescente produção de ālcool incentivada através dos recursos do Programa Nacional do Âlcool, determinaram a expan são desta cultura para novas áreas, nas quais muitas vezes ve rificam-se problemas não encontrados nas regiões produtoras tradicionais, pois estas geralmente apresentam clima e solo favorāveis ao desenvolvimento desta cultura. De acordo com IAA-PLANALSUCAR (1980) a ārea cultivada com cana-de-açūcar no Brasil em 1980 apresentou um acréscimo de 7,11\% em relação a 1979.

Entre os problemas que poderão surgir em āreas de expansão ou em ăreas tradicionais, com a implantação de no vas prăticas, estā a salinidade do solo.

Na Região Norte Fluminense, pode-se constatar a través dos resultados de condutividade elétrica, determinados pela seção de Solos e Adubação do IAA-PLANALSUCAR, que mui- 
tas āreas da Baixada de Campos-RJ apresentam indices elevados de salinidade, prejudicando o rendimento agrícola e industrial da cultura de cana-de-açūcar. Esta situação poderā se ampliar com a implantação do projeto de Irrigação proposto para a região, caso não se faça um manejo adequado da āgua.

Apesar de haver alta correlação negativa entre salinidade e produtividade, sua influência no desenvolvimento e nutrição mineral da cana-de-açūcar no Brasil, não tem merecido atenção, o que nos levou à propor este trabalho com os seguintes objetivos.

- verificar a influência de fontes de sódio no crescimento inicial de cinco cultivares de ca na-de-açūcar, atravēs da produção de matēria seca,

- determinar o efeito dos sais de sōdio $\left(\mathrm{Na}_{2} \mathrm{SO}_{4}\right.$ e NaCl) sobre a concentração de nutrientes nas folhas, e,

- observar diferenças no comportamento das cultivares. 
2. REVISÃO BIBLIOGRAFFICA

Os problemas decorrentes da salinidade do solo no desenvolvimento da cana-de-açūcar têm merecido diversos es tudos, nos quais, observa-se que as concentrações elevadas de sais no substrato podem afetar esta cultura desde a germinação até o final de seu ciclo, no rendimento agrỉcola e industrial.

Salinidade e Germinação:

BARNES (1964), cita que os sais, quando em excesso, podem diminuir ou até inibir a germinação da cana-de-a çücar. SHEN e TUNG (1964), verificaram, em ensaios conduzidos em casa de vegetação, que havia decréscimo na germinação e no desenvolvimento das raízes da cana-de-açūcar, quando elevavase a concentração de NaCl. Os estudos de RIZK e NORMAND (1966), mostram que a cultivar CP47-193 não germinava quando a concen 
tração de sais no solo era de $0,91 \%$ a $1,5 \%$.

O efeito salino sobre a germinação da cana-deaçūcar pode manifestar-se em diferentes intensidades de acordo com a cultivar.

FOGLIATA e ASO (1964), verificaram em experimen tos conduzidos em áreas com diferentes teores de sais no solo, que a cultivar CP29-116 comportou-se como mais tolerante quando comparada com as cultivares CP34-120 e TUC2645.

IIU (1967), estudando o comportamento de $10 \mathrm{cul}$ tivares de cana-de-açūcar, em relação a tolerância à salinidą de, observou que com condutividade elétrica (C.E.)* de 5 mmos/ cm algumas cultivares jā apresentavam redução na germinação , enquanto que a cultivar PRI028 era capaz de desenvolver-se em solos que apresentavam condutividade elētrica de $20 \mathrm{mmhos} / \mathrm{cm}$.

BONNET (1968), verificou que para uma condutivi dade elétrica de 8 mmhos/cm a cultivar poJ28-78 germinava, po rēm não se desenvolvia, sendo que, para a cultivar co290 esta condição provocava a morte.

VALDIVIA e PINNA (1977), estudando a cultivar H32-8560, em condições de campo, encontraram alta correlação negativa $(R=0,80 * *)$ entre germinação e salinidade do solo; os autores concluiram que para se obter boa germinação (> 85\%) seria necessārio que a salinidade fosse menor que $5 \mathrm{mmhos} / \mathrm{cm}$; havendo forte redução na germinação (50\%) para uma condutividade elētrica do solo de 9,7 mmhos/cm.

(*) Condutividade Elētrica obtida em pasta saturada. 
Salinidade e Rendimento Agrícola:

Além do efeito depressivo causado à germinação, a salinidade pode exercer grande influência no desenvolvimento e produtividade da cana-de-açūcar. ROBINSON e WORKER (1965), relatam que quando a condutividade elétrica do solo tornavase ligeiramente superior a 4,2 mmhos/cm havia redução de $50 \%$ na produção da cana-de-açúcar.

SHOJI e SUND (1965), concluiram que a C.E. do solo acima de 4 mnhos/cm afetava severamente o crescimento da cana-de-açúcar. Estudando as cultivares NCo, BERNSTEIN et alii (1966), verificaram que a condutividade elétrica ao redor de 3 mmhos/cm diminuia o rendimento agrícola, das mesmas, em 10\%; quando a C.E. atingia $5 \mathrm{mmhos} / \mathrm{cm}$ a redução no rendimento passou para $25 \%$.

SYED e EL-SWAIFY (1972), encontraram que as cultivares H50-7209 e NCo310 tiveram suas produções reduzi das em $23 \%$ e $45 \%$ respectivamente, quando plantadas em solos a presentando 8 mmhos/cm de C.E. De acordo com SUND e CLEMENTS (1974), a condutividade elétrica do solo próxima a 3 mmhos/cm já é suficiente para reduzir o rendimento agrỉcola de muitas cultivares de cana-de-açūcar.

BARRETO e VALDIVIA (1979), encontraram em solos jovens e altamente salinos, e na presença da cultivar H328560, redução de $15 \%$ na produção quando os teores de sais no solo eram de $0,6 \%$ (ou $7,6 \mathrm{mmhos} / \mathrm{cm}$ ); para $0,85 \%$ de sais (ou 
11,2 mmhos/cm) havia um declínio de 50\% na produção; Valdivia (1978) citado pelos autores, observou que para C.E. superiores a 3,5 - 4 mmhos/cm havia decrēscimo em produção da cana-de-açú car, e que este efeito se tornava mais drástico quando a cultura tinha maior idade $(26,5$ meses $)$ do que para canas de 15,5 meses.

FASIHI e AHMAD (1967), testando o comportamento de 25 cultivares de cana-de-açúcar a diferentes teores de sais no solo, observaram que as cultivares CoL33; CoL54; CoL38 e CoL48, davam consideravelmente melhores resultados, sugerindo, que a utilização de cultivares mais tolerantes, aos efeitos dos sais, seria uma prática que permitiria a utilização de áreas com problemas salinos não muito severos.

Salinidade e Rendimento Industrial:

Entre os primeiros estudos relativos aos problemas da salinidade na qualidade industrial da cana-de-açúcar encontra-se ZERBAN (1913), verificando que a elevação da concentração de sais no solo provocava decréscimo na qualidade industrial, citando que a $0,23 \%$ de sais no solo o caldo apresentava: $\operatorname{brix}=21,0 \%$, sacarose $=18,3 \%$, glicose $=1,3 \%$ e pureza $=87,1 \%$; quando a porcentagem de sais passava para 0,46 tinha-se: $\operatorname{brix}=19,3$, sacarose $=15,5$, glicose $=2,5 \%$ e pureza $=$ $80,3 \%$ 
MANNOF (1939), relata que a irrigação com āgua salina elevava o teor de sais no solo, os quais aumentavam os teores de cinzas do caldo, ocorrendo, aumento na produção de melaço e prejuizos na qualidade industrial, atravēs do decrēs cimo do brix, sacarose e pureza. Resultados semelhantes são apresentados por POE (1942), sugerindo não cultivar-se a cana -de-açūcar em regiões com teores de $\mathrm{NaCl}$ no solo superiores a $0,15 \%$.

Segundo EVANS (1959), a redução do rendimento in dustrial manifestada pela cana, em solos salinos, está ligada aos baixos teores de $\mathrm{N}$ e $\mathrm{P}$ na folha resultante do efeito inibidor do ion cloreto sobre a absorção destes nutrientes.

FOGLIATA e ASO (1964), observaram em estudos de campo que o crescimento e o conteúdo de sacarose não foram afetados quando a C.E. do solo era menor que 0,73 mmos/cm $(0,043 \%$ de sais), no entanto estas duas características diminu iam para C.E. superiores a 1,95 mmhos/cm $(0,102 \%$ de sais); es tes autores concluem que os sais do solo afetam desfavoravelmente o rendimento sacarino prircipalmente de duas formas: in crementando a atividade das carbohidrases e elevando o conteú do de cinzas no caldo, que, por suas propriedades melacigênicas darão maior produção de melaço em detrimento da quantidade de açūcar cristalizado.

MARETZKI et alii (1972), citam que houve elevação na acumulação de sacarose, acompanhada pela baixa concentração de açūcares redutores e pelo decréscimo da atividade 
da invertase quando diminuia-se o potencial osmótico do solo. HUMBERT (1973), relata qua a cana-de-açūcar pro cedente de terrenos salinos apresenta caldo de baixa qualidade com alto conteūdo de sais que tendem a aumentar as incrustações durante o cozimento.

Salinidade e Nutrição:

JOSHI e NAIK (1980), utilizaram diferentes fontes de sais: $\mathrm{NaCl} ; \mathrm{Na}_{2} \mathrm{SO}_{4} ; \mathrm{MgCl}_{2}$ e $\mathrm{MgSO}_{4}$, para verificar seus efeitos no desenvolvimento da cultivar Co740, as plantas cres ceram em solução nutritiva e receberam concentração dos diferentes sais para produzir no substrato C.E. de 10 mmos/cm, os resultados mostram que: a salinidade provocada pelo sulfato foi mais tóxica do que a do cloreto, causando, maior inibição no crescimento, redução na sintese de clorofila e na atividade da PEPcase, e decréscimo na absorção de $\mathrm{K}$ e Ca, mas estimu lou a redutase do nitrato; o grau de toxidez dos diferentes ions em ordem decrescente foi $\mathrm{SO}_{4}^{-2}>\mathrm{Na}^{+}>\mathrm{Cl}^{-}>\mathrm{Mg}^{+2}$. Os es tudos de HAYWARD e WALDEIGH (1949), relatam que o ion sulfato restringe a absorção de Ca e promove a do Na.

A observação de que o sulfato é mais tóxico para a cana-de-açūcar do que o cloreto é confirmada por JosHI e NAIK (1977).

De acordo com FOGLIATA e ASO (1964) a sensibilí 
dade das plantas ao ion sulfato parece estar relacionada com a tendência de que altas concentrações de sulfato limitam a absorção do cálcio, aumentando as de sódio e potássio alteran do o balanço catiônico na planta. Pois conforme MILLAR (1955), o conteúdo equivalente catiônico, particularmente de Ca, Mg e $K$, de uma planta é aproximadamente constante.

O maior grau de toxidez de um sal, segundo RIZK e NORMAND (1969), pode ser devido a fatores do meio ambiente e inerentes à cultivar, e relatam que a toxidez dos ions, em cana-de-açūcar cultivada na Louisiana, segue a ordem: $\mathrm{Na}^{+}>$ $\mathrm{Cl}^{-}>\mathrm{SO}_{4}^{-2}>\mathrm{Ca}^{+2}$.

SYED e EL-SWAIFY (1973), encontraram redução nos teores de nitrogênio quando a NCo310 e H50-7209 se desenvolve ram na presença de $\mathrm{NaCl}$ e $\mathrm{Na}_{2} \mathrm{SO}_{4}$, em solos com C. E. de 2 , 4 , 6 e 8 mmhos/cm, provocados pelos respectivos sais.

JOSHI e NAIK (1980), trabalhando com a 'Co740' em solução nutritiva com C.E. de $10 \mathrm{mmhos} / \mathrm{cm}$, provocada por $\mathrm{NaCl}, \mathrm{Na}_{2} \mathrm{SO}_{4}, \mathrm{MgCl}_{2}$ e $\mathrm{MgSO}_{4}$, observaram acréscimo na concentração de $\mathrm{N}$ que coincidia com a estimulação da redutase do ni trato. Aumentos nos teores de aminoācidos, em folhas de canade-açūcar, estimulados pela concentração de sais, são relatados por KORTSCHACK (1975).

SYED e EL-SWAIFY (1973) verificaram os efeitos de $\mathrm{NaCl}, \mathrm{Na}_{2} \mathrm{SO}_{4}$ e āgua do mar, em concentrações que correspon diam 2, 4, 6 e 8 mmhos/cm, na composição das cultivares NCo310 e- H50-7209 concluindo que: o teor de $\mathrm{K}$ permaneceu inalterado com as doses de $\mathrm{NaCl}$ e āgua do mar, mas decresceu 
com as de $\mathrm{Na}_{2} \mathrm{SO}_{4} ;$ o conteūdo de Ca foi reduzido em todos os tratamentos, sendo mais acentuado na presença de $\mathrm{Na}_{2} \mathrm{SO}_{4} ; 0 \mathrm{Mg}$ apresentou acréscimos em sua concentração, nos diferentes tra tamentos; o teor de $\mathrm{P}$ não sofreu alteração na cultivar NCo 310, mas aumentou significativamente na H50-7209. INSTITUT OF SUGAR RESEARCH (1973) estudando as cultivares UCW5465 e HJ 5747 não encontrou correlação entre os teores de $\mathrm{P}$ e niveis de salinidade.

RICHARDS (1973), relata que em geral o aumento do teor de sódio no substrato resulta em decréscimo de acumulação de cālcio, magnésio e potāssio na planta; muitas espécies vegetais são mais sensĩveis ao sulfato do que ao cloreto, quando em concentrações isosmōticas; a sensibilidade das plantas a altas concentrações de sulfato é devido à limitação na absorção do cālcio.

IYENGAR et alii (1977) observaram que a medida que elevava-se a concentração de Na na solução nutritiva, havia redução no crescimento e elevação nos teores de $\mathrm{K}$, Ca $\mathrm{e}$ Mg nas folhas das cultivares Co419 e Co577.

HASSAN et alii (1970a), encontraram correlação negativa entre teores dos sais $\mathrm{Na}_{2} \mathrm{SO}_{4}, \mathrm{MgSO}_{4}$ e $\mathrm{CaCl}_{2}$ no solo, causando uma condutividade elétrica de 16 mmhos/cm, e a absor ção de $\mathrm{P}, \mathrm{K}, \mathrm{Ca}, \mathrm{Fe}$ e $\mathrm{Cu}$, em plantas de cevada.

HASSAN et alii (1970b) concluem que nas folhas e caule de milho ocorreram decréscimos no acūmulo de P, K, Ca, $\mathrm{Fe}, \mathrm{Cu}$ e Mn quando cultivado em solos com C.E. de 16 mmhos/crn, 
induzida por $\mathrm{Na}_{2} \mathrm{SO}_{4}, \mathrm{MgSO}_{4}$ e $\mathrm{CaCl}_{2}$. MARTIN e BINGHAN (1954), relatam que a adição de sōdio pode resultar em uma grande trans ferência de potássio das raízes para a parte aérea das plantas.

BONNET (1953), observou que em solos salinos com 0,53 a 1,19\% de $\mathrm{NaCl}$ e com uma relação $\mathrm{Ca} / \mathrm{Na}$ entre 2,5 a 3,1 a cana-de-açūcar apresentava seu crescimento bastante reduzido; mas desenvolvia-se satisfatōriamente, quando o solo salino tinha 4,5 a $11,4 \%$ de $\mathrm{Na}$ e a relação $\mathrm{Ca} / \mathrm{Na}$ estava entre 12 a 19,4 .

SYED e EL-SWAIFY (1972), concluem que: comparativamente o efeito da concentração de sais é maior do que o causado pelo tipo de sal empregado, sugerindo desta maneira que o efeito osmótico seja mais responsável pelos prejuizos causados pela salinidade na cana-de-açūcar do que o efeito tó xico ou expecífico de um ion.

HUMBERT (1973), referindo-se aos sintomas provo cados pela salinidade na cana-de-açúcar faz a seguinte descrí ção: a absorção de excesso de sais solūveis queima a ponta das folhas jovens e as margens das folhas velhas; a folhagem murcha indicando as dificuldades que esta passando a cultura para absorver a āgua necessāria para seu desenvolvimento normal; os entrenós tornam-se curtos; em estägio mais avançado as folhas velhas secam seguidas das mais novas, atē finalmente a seca do palmito e a morte da planta.

De acordo com MASS e HOFFMAN (1977), a cana-de -açúcar é um cultivo semi-tolerante à salinidade do solo, ini 
ciando decréscimos na produção quando a C.E. do extrato de sa turação atinge 1,7 mmhos/cm, acima deste limite, para cada unidade de salinidade verifica-se um decréscimo de 5,9\% na pro dução. 
3. MATERIAL E METODOS

O experimento foi conduzido em casa de vegetação do Departamento de Química da Escola Superior de Agricultura "Luiz de Queiróz", Piracicaba-SP, iniciado em 17-3-81.

Utilizou-se as cultivares de cana-de-açūcar (Saccharum spp): CB45-3; RB70194; RB725828; NA56-79 e CP51-22, procedentes da Seção de Melhoramento da Coordenadoria Regicnal Sul do IAA-PLANALSUCAR, em Araras-SP.

Após a obtenção de gemas isoladas, de acordo com o sistema apresentado por SILVA (1975), as mesmas foram colocadas em bandejas plásticas contendo areia grossa lavada. Após a germinação as mudas receberam uma irrigação semanal com solução nutritiva completa conforme descrito por SARRUGE(1975), até atingirem aproximadamente $10 \mathrm{~cm}$ de altura, aos 35 dias.

Neste estágio de desenvolvimento procedeu-se 0 transplante, de 4 mudas da mesma cultivar para recipiente plás tico, com capacidade para 15 litros de solução. Estes recipientes foram subdivididos internamente com chapas de PVC para 
separação das cultivares, e revestidos externamente com lona plástica preta, para evitar a penetração de luz e controlar o desenvolvimento de algas. Empregou-se espuma de plástico pa ra a fixação das plantas em copos de polietileno (usado para café). Fez-se o controle da aeração das soluções atravēs de capilares. O esquema representado na figura l é o mesmo que foi utilizado por AZEREDO (1982).

Após o transplante as mudas receberam solução nutritiva completa, segundo SARRUGE (1975), durante 30 dias a té apresentarem aspecto uniforme, quando tiveram inīcio os tratamentos com 5 níveis de sódio provenientes de 2 fontes $\left(\mathrm{NaCl}\right.$ e $\left.\mathrm{Na}_{2} \mathrm{SO}_{4}\right)$. O delineamento experimental foi o inteiramente ca sualizado, com esquema de parcelas subdivididas e 4 repetições. As concentrações de sōdio nas soluções nutritivas dos diferentes tratamentos foram:

Fontes de $\mathrm{Na}$

$\mathrm{Na}_{2} \mathrm{SO}_{4}(0,5 \mathrm{M})$

$\mathrm{NaCl}(\mathrm{M})$
Concentrações de $\mathrm{Na}$ (ppm)

$0 ; 69 ; 138 ; 207 ; 276$ + Solução nutritiva completa

$0 ; 69 ; 138 ; 207 ; 276+$ solução nutritiva completa

As soluções nutritivas acrescidas de doses de Na eram renovadas à cada 10 dias.

Decorridos 50 dias do início dos tratamentos; as plantas foram colhidas e separadas em raízes ; colmos + bai nhas (considerada colmo) e lâminas (consideradas folhas) e le vadas para secar em estufa com circulação forçada de ar 
$70-75: C$ até atingir peso constante.

Após a pesagem da matēria seca das partes consi deradas, procedeu-se a moagem das folhas em moinho tipo wiley, com peneira 20. Os teores de macro e micronutrientes nas folhas, exceto $\mathrm{Cl}$ e Mo, foram determinados analiticamente de acordo com a metodologia descrita por SARRUGE e HAAG (1974).

os dados obtidos foram submetidos a anālises de variāncia conforme PIMENTEL GOMES (1977), determinou-se equações de regressão até 39 grau, sendo considerada como repre sentativa a equação significativa de maior grau. 


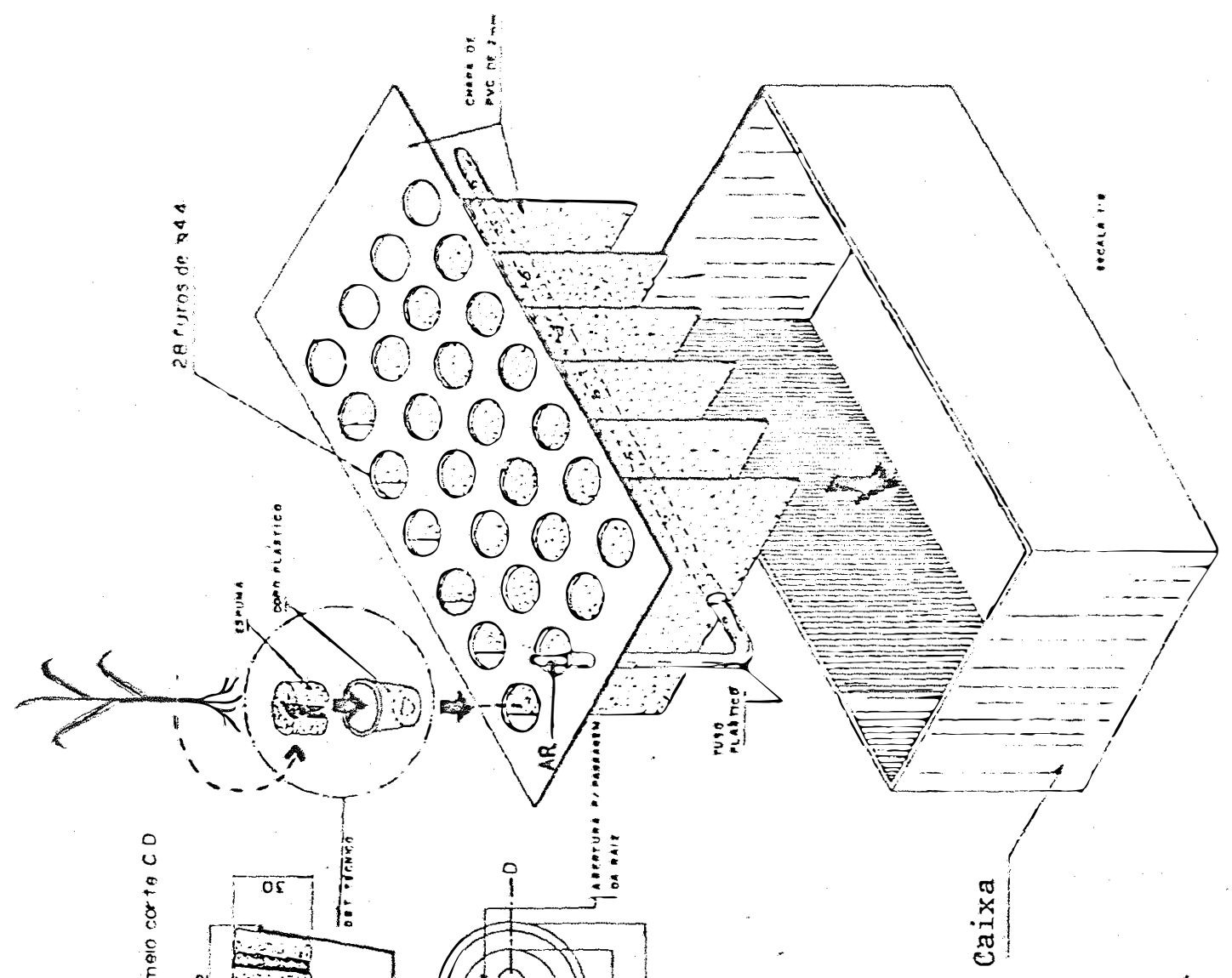

E
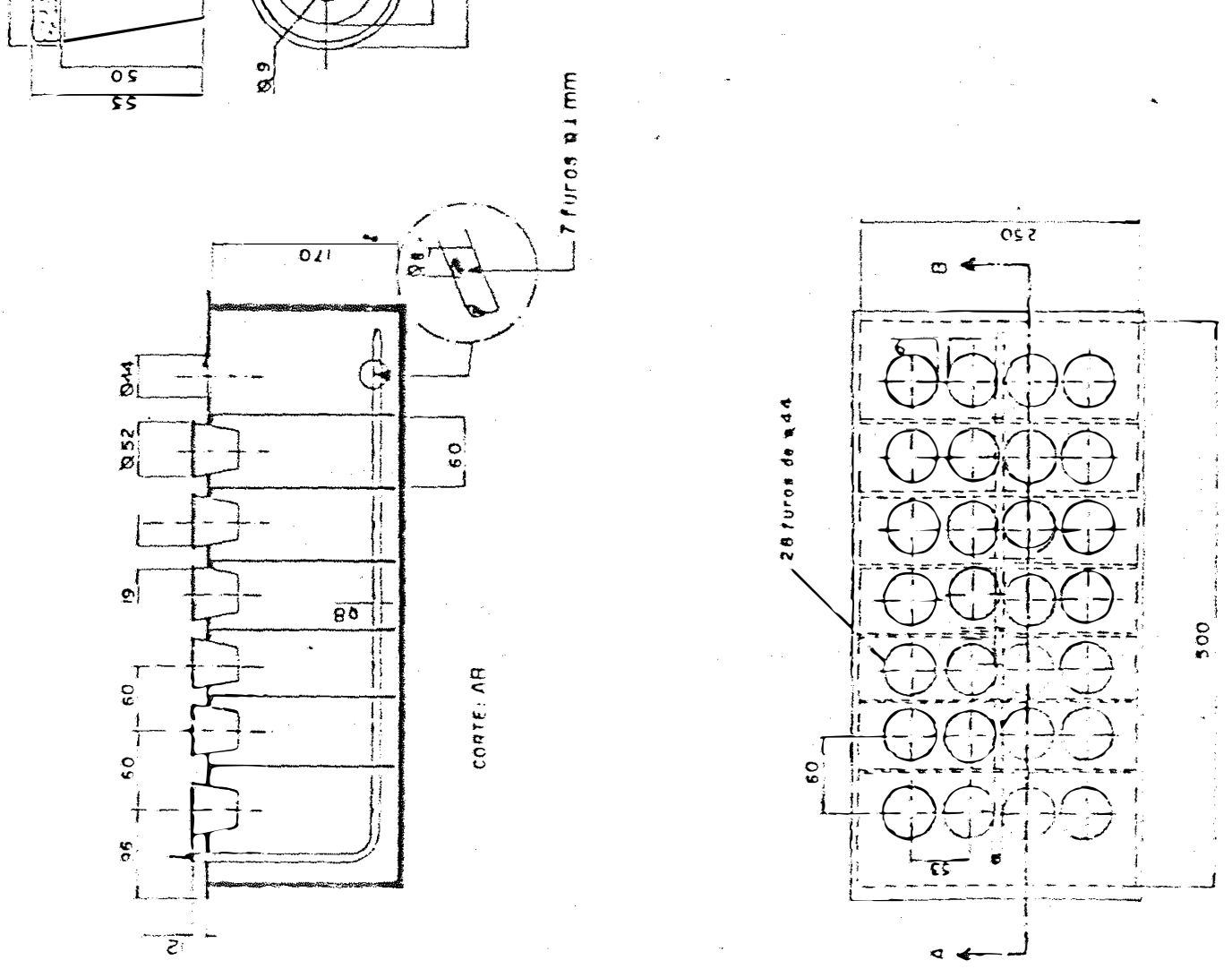
4. RESULTADOS E DISCUSSÃO

\subsection{CRESCIMENTC}

O peso médio de matēria seca das partes das plạn tas, em função dos tratamentos, o resumo da anālise de variância e as equações de regressão podem ser observadas nas tabelas 1,2 e 3 , respectivamente.

Os resultados mostram que para as diferentes par tes houve efeito de dose e cultivar, interagindo com fonte.

As produções de matēria seca de raízes, colmos e folhas da cultivar CB45-3, submetida ao tratamento com $\mathrm{Na}_{2} \mathrm{SO}_{4}$, e de colmos no tratamento com $\mathrm{NaCl}$, foram ajustadas regressões cūbicas com os seguintes parâmetros: 


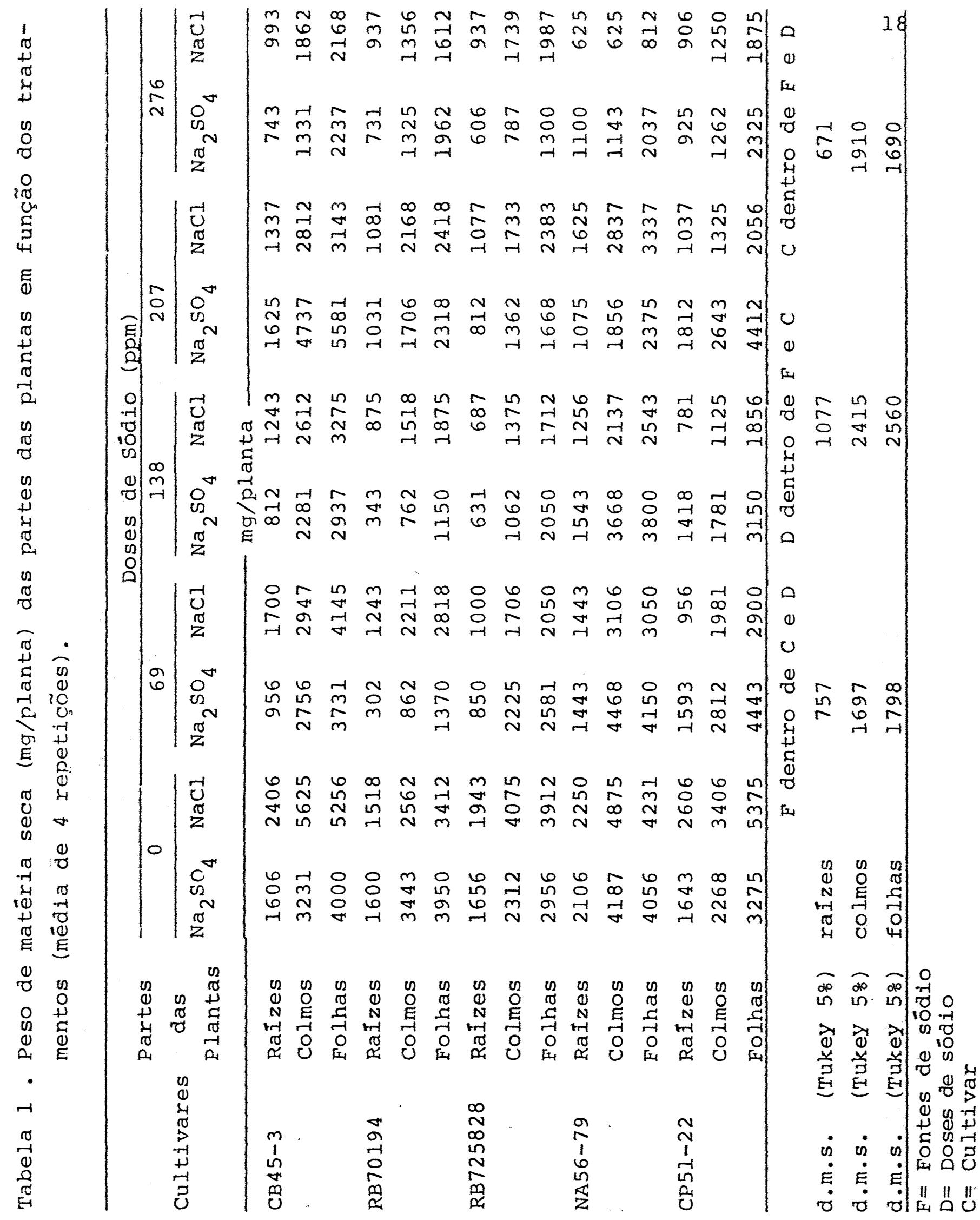


Tabela 2 . Resumo da análise de variância dos valores de peso da matéria seca de raizes, colmos e folhas, das cultivares de cana-de-açūcar, em função da fonte e dose de sódio na solução nutritiva.

\begin{tabular}{|c|c|c|c|c|}
\hline \multirow{2}{*}{$\begin{array}{l}\text { Causas de } \\
\text { variação }\end{array}$} & \multirow[b]{2}{*}{ G.L. } & \multicolumn{3}{|c|}{ ¿uadrados Médios } \\
\hline & & Raizes & Colmos & Folhas \\
\hline & & $\left(x 10^{5}\right)$ & $\left(x 10^{5}\right)$ & $\left(x 10^{5}\right)$ \\
\hline Fonte $(F)$ & 1 & 9,80000 & 5,80717 & 10,42856 \\
\hline Dose (D) & 4 & $71,94497 * *$ & $301,30355 * *$ & $271,56282 * *$ \\
\hline$F \times D$ & 4 & 3,58214 & 29,56206 & 29,12696 \\
\hline Residuo (a) & 27 & 2,71313 & 13,64847 & 15,33857 \\
\hline Parcela & 36 & & & \\
\hline Cultivar (C) & 4 & $19,22373 * *$ & $143,74681 * *$ & $143,05511 * *$ \\
\hline$F \times C$ & 4 & 6,43533 & 17,97268 & $20,30916 *$ \\
\hline$D \times C$ & 16 & 1,46008 & $21,15026 * *$ & $12,63276 *$ \\
\hline$F \times D \times C$ & 16 & 4,38901 * * & $22,53371 * \star$ & $22,75749 * *$ \\
\hline Residuo (b) & 123 & 1,17354 & 9,49865 & 7,43668 \\
\hline Total & 199 & & & \\
\hline $\mathrm{CV}$ 응 (a) & & 42,38 & 50,68 & 42,99 \\
\hline$C V$ 용 (b) & & 27,87 & 42,27 & 29,93 \\
\hline
\end{tabular}

$e^{* *}=$ quadrados mëdios correspondentes a valores de $F$ signifi cativos a $5 \%$ e $1 \%$ de probabilidade, respectivamente. 
Tabela 3. Equações de regressão dos valores de peso de matéría seca (Y) de raízes, colmos e folhas de cultivares de cana-de-açūcar, obtidas em função da fonte e dose de sódio $(x)$, e o coeficiente de determinação $\left(R^{2}\right)$.

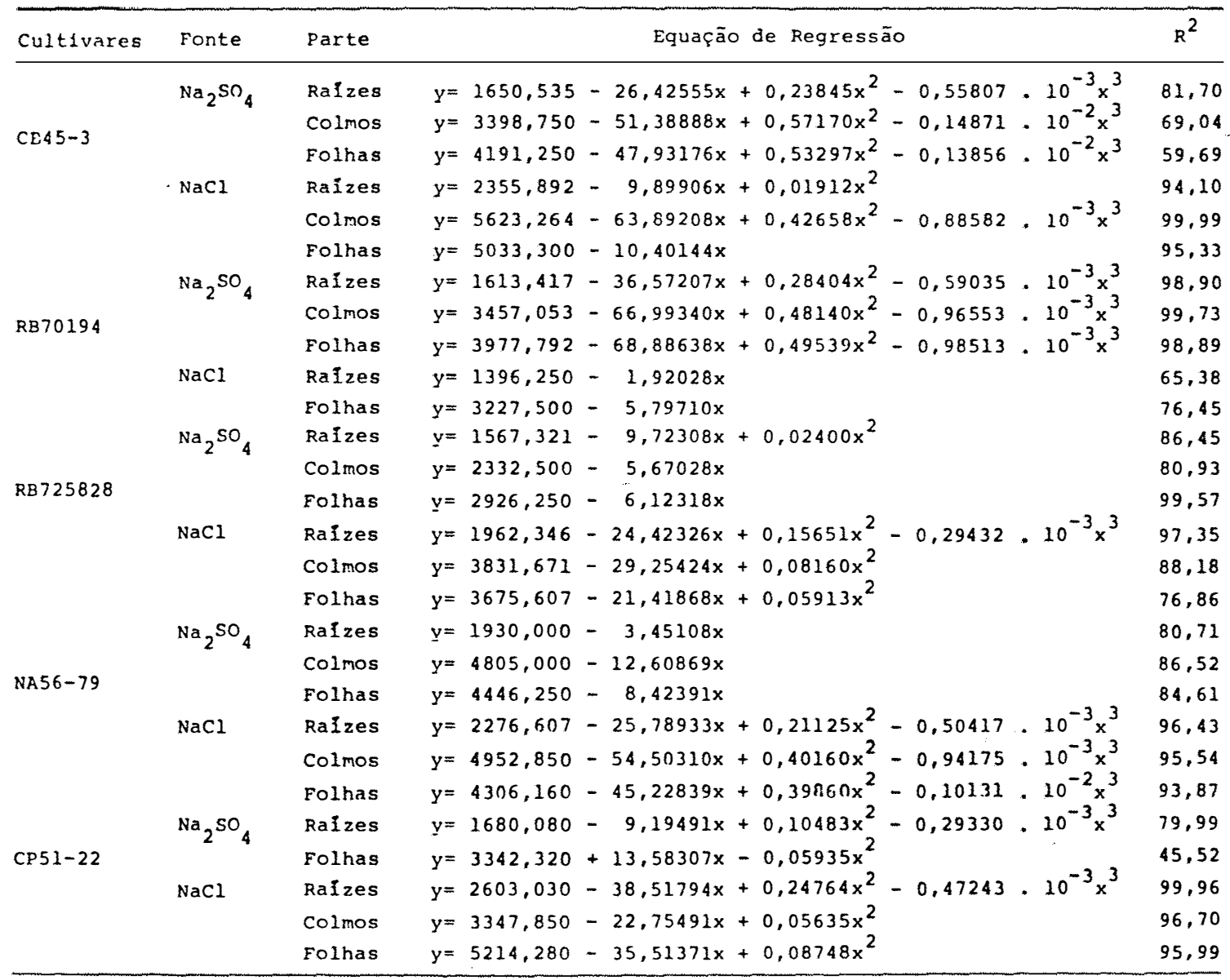




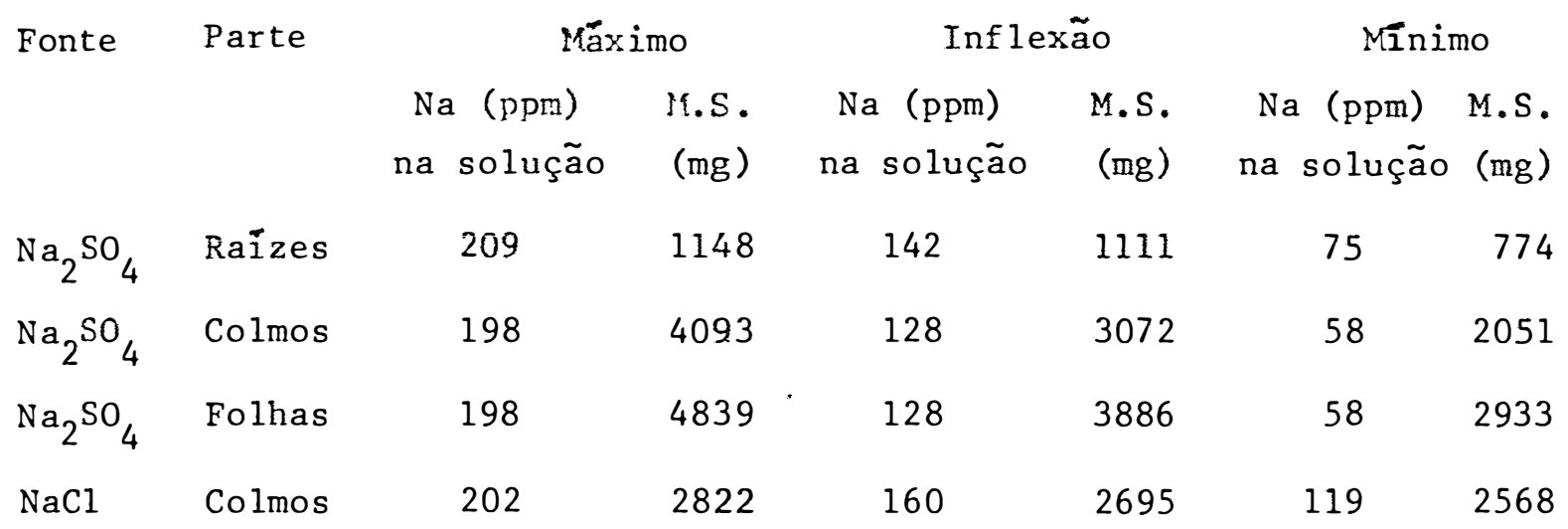

$\mathrm{Na}$ presença de $\mathrm{NaCl}$, ajustou-se, para raízes re gressão quadrática com mínimo de $1075 \mathrm{mg}$ correspondente à solu Ção com 259ppm de $\mathrm{Na}$; e para folhas regressão linear com decréscimos de 4,10mg para aumentos de lppm de Na na solução.

o sōdio, na forma de sulfato, afetou a produção de matéria seca das partes da cultivar CB45-3 de modo a aumen tar ou diminuir aquela produção. Dessa maneira a produção de matēria seca diminuiu nas diversas partes quando o Na foi aplicado até a concentração média de $64 \mathrm{ppm}$; desse valor em diante houve acréscimo na quantidade de matēria seca acumulada, atē a concentração média de $202 \mathrm{ppm}$ de Na na solução, ultrap̣as sando a produção, estimada, de matēria seca obtida na ausência do sódio.

A aplicação de $\mathrm{NaCl}$ afetou a matéria seca predo minantemente no sentido de diminuição da mesma.

Para a cultivar RB70194 foram ajustadas regressões cúbicas às produções de matēria seca de raízes, colmos e 
folhas, quando o fornecimento de Na foi através de sulfato, de acordo com os seguintes parâmetros:

Parte

Máximo

Inflexão

Mínimo

$\mathrm{Na}$ (ppm) M.S. Na (ppm) M.S. Na (ppm) M.S. na solução (mg) na solução ( $\mathrm{mg})$ na solução (mg)

$\begin{array}{rrrrrrr}\text { Raizes } & 231 & 1045 & 160 & 618 & 89 & 192 \\ \text { Colmos } & 233 & 1769 & 166 & 1187 & 99 & 606 \\ \text { Folhas } & 236 & 2363 & 167 & 1710 & 98 & 1057\end{array}$

Para a fonte $\mathrm{NaCl}$ o crescimento das raizes e fo lhas sofreu decréscimo linear de 1,92mg e 5,79mg, respectivamente, para incrementos de lppm de Na na solução.

A produção de matéria seca das partes da cultivar RB70194 foi influenciada negativamente por ambas as fontes de sódio, com excessão dos colmos que não foram afetados pela presença de $\mathrm{NaCl}$.

A adição de sulfato de sódio mostrou, para as concentrações mạis baixas de $\mathrm{Na}$, efeito acentuadamente depres sivo sobre a acumulação de matēria seca das partes, a qual atingiu a mínima produção estimada numa concentração média de 95ppm de $\mathrm{Na}$; a partir daí observa-se incrementos na matēria seca das partes, até a concentração média de $233 \mathrm{ppm}$ de $\mathrm{Na}$ na solução, porēm sem atingir a produção estimada para a concentração "O ppm".

O desenvolvimento da cultivar RB725828 na presen- 
ça de $\mathrm{Na}_{2} \mathrm{SO}_{4}$ foi traduzido para as raizes por regressão quadrātica com mínimo de $582 \mathrm{mg}$ correspondente a $202 \mathrm{ppm}$ de Na na solução; e para os colmos e folhas por regressão linear decrescente variando, respectivamente, 5,67 e 6,12mg para incrementos de lppm de $\mathrm{Na}$ na solução. Jä para a fonte $\mathrm{NaCl}$ a re gressão ajustada, à produção de matēria seca das raízes, foi cúbica com māximo, inflexão e mínimo de 1047, 911 e 775mg cor respondentes às soluções com 238, 177 e 166ppm de Na na solução; para a matēria seca de colmos e folhas as equações ajustadas foram quadrāticas, apresentando produções mínimas, respectivamente, de 1209 e $1736 \mathrm{mg}$ relativas às soluções com 179 e 18lppm de $\mathrm{Na}$.

Para a cultivar RB725828 verifica-se que a adição de Na na forma de sulfato e de cloreto acarretou decrésci mo na acumulação de matēria seca pelas partes das plantas.

Para as raízes, na presença de $\mathrm{NaCl}$, até a concentração calculada de $116 \mathrm{ppm}$ de Na ocorreram decrēscimos pro nunciados na produção de matēria seca. A partir desse ponto quantidades adicionais de $\mathrm{Na}$ na solução provocaram ligeiro au mento na matēria seca, sendo o efeito depressivo do elemento minimizado na concentração de $238 \mathrm{ppm}$.

As plantas da cultivar NA56-79, que receberam $\mathrm{Na}_{2} \mathrm{SO}_{4}$ ' apresentaram produção de matēria seca de raízes, colmos e folhas segundo regressão linear, os decrēscimos devido a incrementos de lppm de sōdio na solução foram, respectivamente, de $3,44,12,60$ e $8,42 \mathrm{mg}$. Enquanto que para o forneci- 
mento de $\mathrm{NaCl}$, à produção de matēria seca das raízes, colmos e folhas ajustaram-se regressões cūbicas, com os seguintes pon tos:

Parte

\begin{tabular}{|c|c|c|c|c|c|c|c|}
\hline \multicolumn{3}{|c|}{ Māximo } & \multicolumn{2}{|c|}{ Inflexão } & \multicolumn{3}{|c|}{ Mínimo } \\
\hline & $\begin{array}{c}\text { (ppm) } \\
\text { solução }\end{array}$ & $\begin{array}{l}\text { M.S. } \\
(\mathrm{mg})\end{array}$ & $\begin{array}{c}\mathrm{Na}(\mathrm{ppm}) \\
\text { na solução }\end{array}$ & $\begin{array}{l}\text { M.S. } \\
(\mathrm{mg})\end{array}$ & $\begin{array}{c}\mathrm{Na} \\
\mathrm{na}\end{array}$ & $\begin{array}{c}\text { (ppm) } \\
\text { solução }\end{array}$ & $\begin{array}{l}\text { M.S. } \\
\text { (mg) }\end{array}$ \\
\hline & 189 & 1545 & 139 & 1442 & & 90 & 1299 \\
\hline & 172 & 2667 & 142 & 2615 & & 111 & 2563 \\
\hline & 179 & 3171 & 131 & 2945 & & 83 & 2718 \\
\hline
\end{tabular}

A adição de sōdio atravēs das fontes sulfato e cloreto, proporcionou decréscimos na produção de matéria seca das diferentes partes da cultivar NA56-79.

Deve-se salientar que para a fonte $\mathrm{NaCl}$, a elevação da concentração de sōdio na solução, proporcionou diminuição na produção de matēria seca das raízes, colmos e folhas, a qual se acentuou atē a concentração média de $95 \mathrm{ppm}$ de Na. Acima dessa concentração ocorreu pequeno incremento no acúmulo de matēria seca, diminuindo o efeito depressivo do sōdio atē a concentração média de 180 ppm de Na na solução.

Observou-se para a cultivar CP51-22, que à produção de matēria seca das raízes, em ambas as fontes de $\mathrm{Na}$, sulfato e cloreto, ajustaram-se regressões cúbicas com os parâmetros : 
Parte Fonte

Mäximo

Inflexão

Mínimo

$\begin{array}{cccccc}\mathrm{Na}(\mathrm{ppm}) & \mathrm{M} . \mathrm{S} . & \mathrm{Na} \text { (ppm) } & \text { M.S. } & \mathrm{Na} \text { (ppm) } & \text { M.S. } \\ \text { na solução } & (\mathrm{mg}) & \text { na solução } & (\mathrm{mg}) & \text { na solução } & \text { (mg) }\end{array}$

Raizes $\quad \mathrm{Na}_{2} \mathrm{SO}_{4}$

180

1711

119

1576

58

1442

Raízes $\mathrm{NaCl}$

232

1096

175

913

117

729

Os colmos sofreram redução na produção de matēria seca, quando empregou-se $\mathrm{NaCl}$, traduzida por. regressão quadrātica, com mínimo de $105 \mathrm{lmg}$ correspondente a $266 \mathrm{ppm}$ de Na na solução. A produção de matéria seca das folhas ajustouse regressão quadrātica, com māximo de $4119 \mathrm{mg}$ correspondente a $114 \mathrm{ppm}$ de sódio fornecido como sulfato; e minimo de l6lomg cor respondentes a $203 \mathrm{ppm}$ de sódio na forma de cloreto.

O fornecimento de $\mathrm{Na}_{2} \mathrm{SO}_{4}$ provocou nas raizes da cultivar CP51-22 efeito duplo, acarretando inicialmente decrēscimo na produção de matēria seca das mesmas, até a concen tração calculada de 58ppm; acima desta concentração houve minimização do efeito depressivo do sódio, elevando-se a prodū ção de matéria seca estimada que atingiu valor superior ao encontrado no tratamento com omissão de sódio, na presença de $180 \mathrm{ppm}$ do elemento. Para esta mesma fonte, observa-se que hou ve efeito positivo da adição do $\mathrm{Na}$, atē a concentração estima da de $114 \mathrm{ppm}$, sobre a produção de matéria seca das folhas.

Com excessão das raizes, que revelaram pequena diminuição do efeito depressivo do sōdio na forma de cloreto, entre 117 e $332 \mathrm{ppm}$ de sódio, esta fonte de sódio apresentou 
predominância no sentido de diminuição da produção de matéria seca das diferentes partes.

o confronto dos resultados mostra que para as cultivares RB70194, RB725828 e NA56-79 o fornecimento de sódio tanto na forma de sulfato como de cloreto, afetou negativamente a acumulação de matéria seca. Nas cultivares CB45-3 e CP51-22 observou-se que o sulfato de sódio provocou aumento e diminuição na produção de matēria seca, o efeito benēfico ficou restrito a uma determinada faixa de concentração; $0 \mathrm{NaCl}$ afetou reduzindo a produção de matéria seca.

SYED e EL-SWAIFY (1972) relatam que o fornecimento de NaCl não afetou o crescimento da cana-de-açūcar (cul tivares NCo310 e H50-7209) quando fornecido em baixas e médias concentrações ( 2 e $4 \mathrm{mmhos} / \mathrm{cm}$ ); ocorrendo redução acentuada no crescimento em altas concentrações (6 a 8 mmhos/cm); enquanto que a adição de $\mathrm{Na}_{2} \mathrm{SO}_{4}$ em nível médio ( $6 \mathrm{mmhos} / \mathrm{cm}$ ) beneficiou o desenvolvimento das cultivares.

Embora as cultivares estudadas tenham apresenta do diferenças no comportamento, pode-se verificar que concentrações em torno de $200 \mathrm{ppm}$ de $\mathrm{Na}$ na solução, independente da fonte, acarretaram decréscimo na produção de matéria seca das mesmas.

Essas diferenças foram observadas por FASIHI e AHMAD (1967) e SYED e EL-SWAIFY (1972) mostrando que há um comportamento diferenciado de cultivares de cana-de-açūcar na presença de condições salinas. 
No presente trabalho, houve efeito depressivo do sōdio, fornecido como sulfato ou cloreto, sobre o crescimento inicial da cana-de-açūcar evidenciando desta maneira a toxidez do ion específico, södio. O efeito maior ou menor provoca do pelo sulfato ou pelo cloreto foi em função de cultivar,'da parte da planta e da dose, dificultando portanto a determinação do grau de toxidez destes ions.

Trabalhos conduzidos por HAYWARD e WADLEIGH (1949); JOSHI e NAIK (1977), JOSHI e NAIK (1980), relatam ser o sulfato mais tóxico para a cana-de-açūcar do que o cloreto. Mas de acordo com RIZK e NORMAND (1969) a maior toxidez de determinado sal pode ser devido a fatores do meio ambiente e à cultivar.

\subsection{NITROGENIO}

Os resultados médios das concentrações de nitro gênio nas folhas das diferentes cultivares, e o resumo da anā lise de variância encontram-se nas tabelas 4 e $5 ;$ e as equações de regressão na tabela 6 .

Observa-se que houve efeito de fonte, dose e cultivar, com interação. 
Tabela 4. Concentração de nitrogênio (ơ) nas folhas das diferentes cultivares de cana-de-açũcar, em função dos tratamentos. (doses de sódio).

\begin{tabular}{|c|c|c|c|c|c|c|c|c|c|c|}
\hline \multirow[t]{2}{*}{ Cultivar } & \multicolumn{2}{|c|}{0 ppm } & \multicolumn{2}{|c|}{69 ppm } & \multicolumn{2}{|c|}{$138 \mathrm{ppm}$} & \multicolumn{2}{|c|}{$207 \mathrm{ppm}$} & \multicolumn{2}{|c|}{276 ppm } \\
\hline & $\mathrm{Na}_{2} \mathrm{SO}_{4}$ & $\mathrm{NaCl}$ & $\mathrm{Na}_{2} \mathrm{SO}_{4}$ & $\mathrm{NaCl}$ & $\mathrm{Na}_{2} \mathrm{SO}_{4}$ & $\mathrm{NaCl}$ & $\mathrm{Na}_{2} \mathrm{SO}_{4}$ & $\mathrm{NaCl}$ & $\mathrm{Na}_{2} \mathrm{SO}_{4}$ & $\mathrm{NaCl}$ \\
\hline CB45-3 & 2,06 & 1,91 & 1,84 & 1,72 & 2,00 & 1,74 & 1,88 & 1,61 & 1,94 & 1,75 \\
\hline RB70194 & 1,82 & 1,68 & 2,02 & 1,58 & 2,04 & 1,67 & 1,87 & 1,47 & 1,80 & 1,66 \\
\hline RB725828 & 2,17 & 2,15 & 2,34 & 1,97 & 2,28 & 2,01 & 2,29 & 1,90 & 2,19 & 1,82 \\
\hline NA56-79 & 2,28 & 2,08 & 2,21 & 1,85 & 2,23 & 1,98 & 2,22 & 1,77 & 2,23 & 2,09 \\
\hline CP51-22 & 2,04 & 1,87 & 1,83 & 1,77 & 2,00 & 1,91 & 2,10 & 1,67 & 2,22 & 1,68 \\
\hline d.m.s. (Tukey & (y 58) & $\begin{array}{l}\text { Fonte } \\
\text { Dose } \\
\text { Culti }\end{array}$ & $\begin{array}{l}\text { dentro } \\
\text { dentro } \\
\text { ivar den }\end{array}$ & $\begin{array}{l}\text { o de a } \\
\text { de fol } \\
\text { ntro d }\end{array}$ & $\begin{array}{l}\text { oultivar } \\
\text { onte e } \\
\text { de fonts }\end{array}$ & $\begin{array}{l}\text { ex do } \\
\text { cultiv }\end{array}$ & $\begin{array}{r}\text { ose } 0,25 \\
\operatorname{var} 0,35 \\
0,21\end{array}$ & & & \\
\hline
\end{tabular}

Os teores de nitrogênio nas folhas das cultivares CB45-3 e NA56-79 foram influenciados, negativamente, somente pela fonte $\mathrm{NaCl}$, ajustando-lhes regressão quadrática, a presentando concentrações minimas de 1,66 e 1,84\%, correspondentes às soluções com 177,9 e 141,5ppm de sōdio. Já para a 'RB70194' foi o $\mathrm{Na}_{2} \mathrm{SO}_{4}$ que apresentou efeito quadrático do só dio na concentração de $\mathrm{N}$, com māximo de 2,01\% de $\mathrm{N}$ nas folhas, para 125, Ippm de sódio na solução. Para os teores de $\mathrm{N}$ nas fô lhas das cultivares RB725828 e CP51-22, na presença de $\mathrm{NaCl}$, ajustaram-se regressões lineares decrescentes com diminuição 


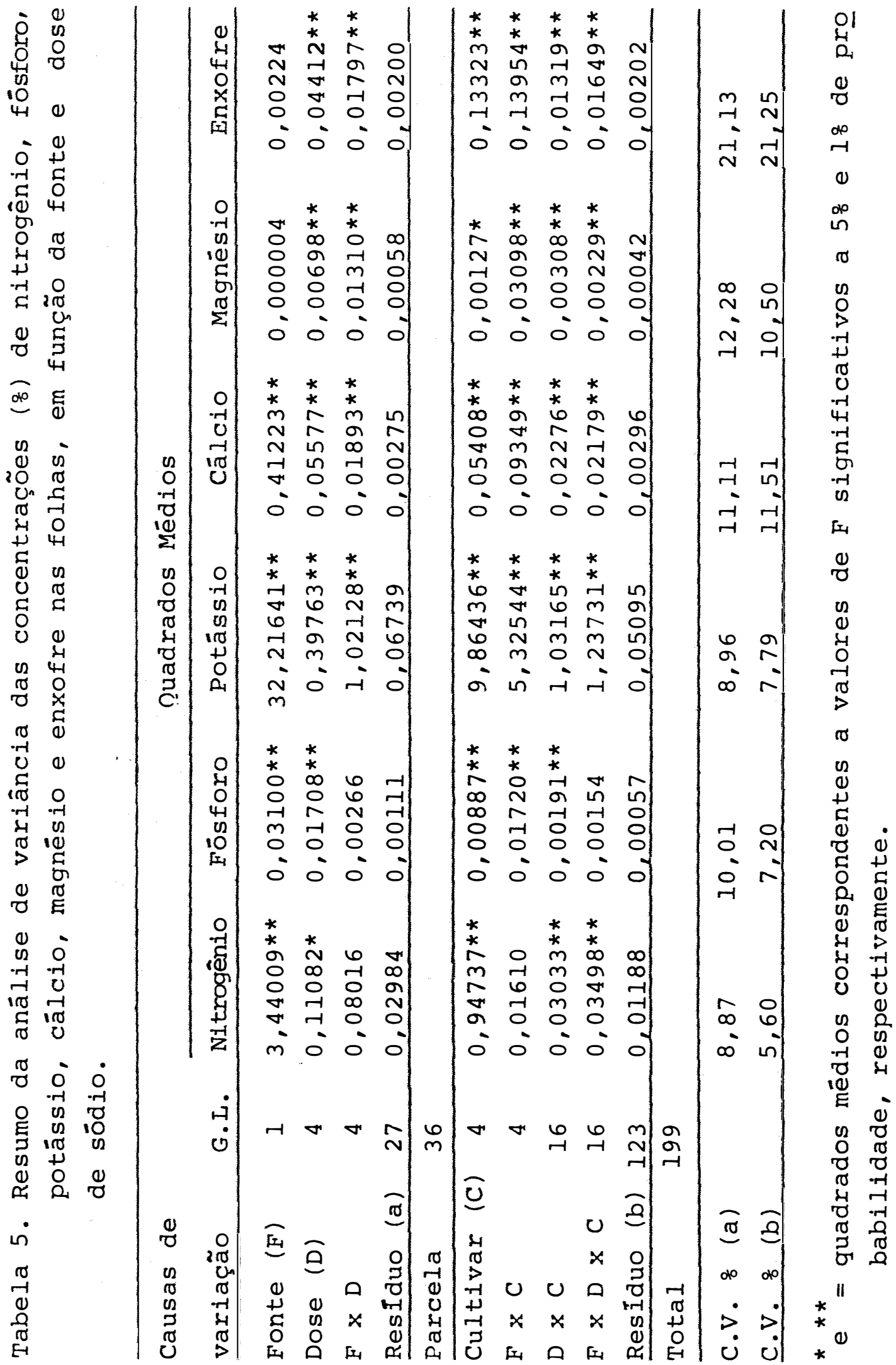


de 0,07 e $0,05 \%$ nos teores de $N$ entre cada dose empregada; pa ra a RB725828 houve efeito do sōdio, na forma de $\mathrm{Na}_{2} \mathrm{SO}_{4}$, ajus tando-se regressão quadrātica com máximo de $2,32 \%$ de $\mathrm{N}$ para $137,5 \mathrm{ppm}$ de $\mathrm{Na}$, e para a CP51-22 regressão cúbica com pontos de minimo, inflexão e máximo iguais a 1,86; 2,03 e 2,21\% de $\mathrm{N}$, correspondentes às soluções com 70,8; 170,3 e 269,8ppm de sōdio.

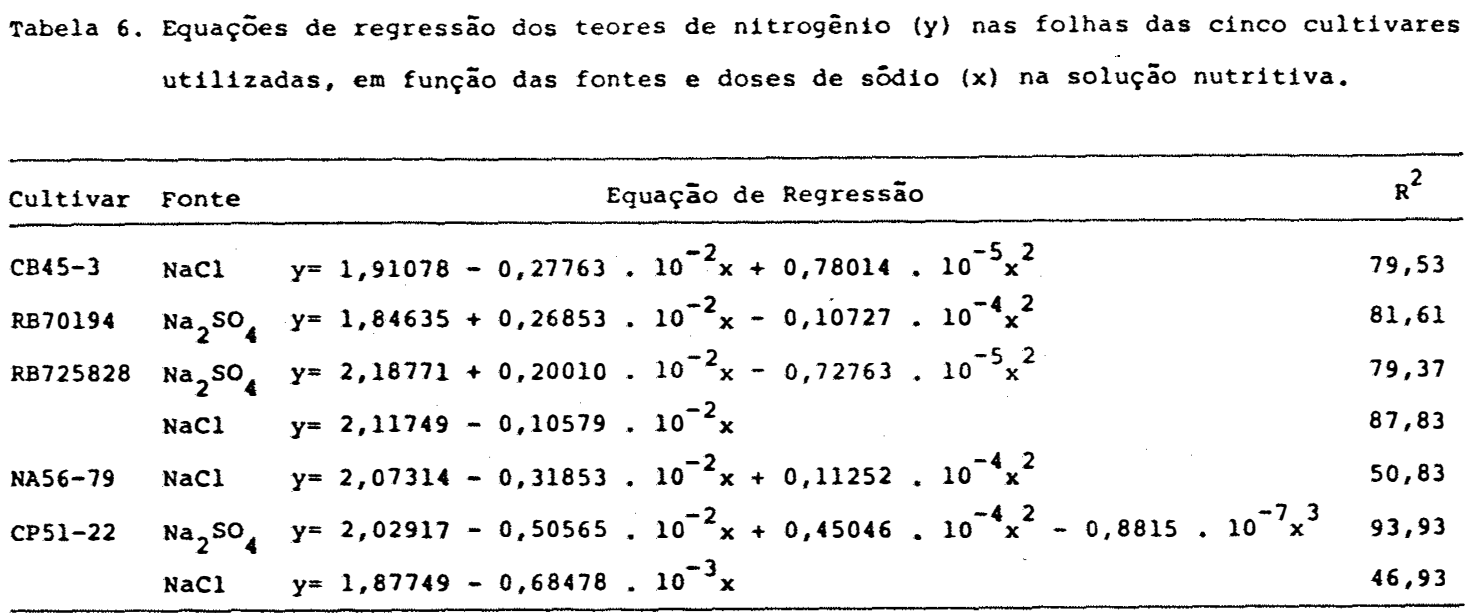

A adição de sulfato de sōdio, até a concentração média de 131,3ppm de Na, acarretou elevação nos teores es timados de $\mathrm{N}$ nas folhas das cultivares RB70194 e RB705828, que tornaram-se superiores aos determinados pelo tratamento com omissão de Na. Para a cultivar CP51-22 observou-se que aquela fonte de Na produziu decréscimo e elevação dos teores de nitrogênio nas folhas, deste modo, os decréscimos foram ve rificados até a concentração estimada de $70,8 \mathrm{ppm}$ de $\mathrm{Na}$ na solução; acima deste ponto a adição de Na, até 269,8 ppm, propor 
cionou efeito positivo na concentração de $N$, atingindo valores superiores aos obtidos no tratamento com omissão de sōdio.

O fornecimento de $\mathrm{NaCl}$ se caracterizou pelo efeito predominante negativo, sobre os teores de nitrogênio nas folhas das cultivares.

Os resultados de SYED e EL-SWAIFY (1973) obtidos com as cultivares NCo310 e H50-7209, revelam que a presença de $\mathrm{NaCl}$ e $\mathrm{Na}_{2} \mathrm{SO}_{4}$, em concentrações de $2,4,6$ e 8 mmhos/cm, proporcionou redução no teor de $\mathrm{N}$.

JOSHI e NAIK (1980), trabalhando com uma concen tração mais elevada, 10 mmhos/cm, provocada por $\mathrm{NaCl}, \mathrm{Na}_{2} \mathrm{SO}_{4}$ ' $\mathrm{MgCl}_{2}$ e $\mathrm{MgSO}_{4}$, verificaram que houve elevação no teor de $\mathrm{N}$ nas folhas da cultivar Co740, coincidindo com a estimulaçã da redutase do nitrato.

Pode-se portanto sugerir que o teor de nitrogênio nas folhas da cana-de-açūcar cultivada em condições salinas, será influenciado pela cultivar, pelo tipo e concentração do sal no substrato.

4.3. FOSFORO

A concentração média de fósforo nas folhas, em função das fontes e doses de sódio, e a anālise de variância resumida são apresentadas nas tabelas 7 e 5 , e as equações de 
regressão na tabela 8 .

Tabela 7. Concentração de fósforo (\%) nas folhas das diferentes cultivares de cana-de-açūcar, em função dos trạ tamentos (doses de sódio).

\begin{tabular}{|c|c|c|c|c|c|}
\hline & 0 pprn & 69 ppm & 138 posn & 207 ppm & 276 ppm \\
\hline
\end{tabular}

\begin{tabular}{lllllllllll} 
CB45-3 & 0,34 & 0,38 & 0,30 & 0,31 & 0,31 & 0,30 & 0,28 & 0,28 & 0,31 & 0,36 \\
RB70194 & 0,29 & 0,35 & 0,30 & 0,27 & 0,31 & 0,32 & 0,33 & 0,36 & 0,38 & 0,35 \\
RB725828 & 0,43 & 0,33 & 0,37 & 0,29 & 0,39 & 0,29 & 0,39 & 0,32 & 0,41 & 0,35 \\
NA56-79 & 0,38 & 0,32 & 0,34 & 0,27 & 0,34 & 0,30 & 0,33 & 0,29 & 0,34 & 0,36 \\
CP51-22 & 0,37 & 0,32 & 0,33 & 0,29 & 0,36 & 0,32 & 0,31 & 0,32 & 0,36 & 0,36 \\
\hline
\end{tabular}

Fonte dentro de cultivar e dose 0,05

d.m.s. (Tukey 5\%) Dose dentro de fonte e cultivar 0,07

Cultivar dentro de parte e dose 0,05

Observa-se que houve efeito, com interação, de cultivar e fonte e de cultivar e dose.

Ajustou-se aos teores de fósforo nas folhas das cultivares CB45-3; RB725828 e CP51-22, regressão quadrática, para ambas as fontes de sódio, com mínimo de 0,29; 0,38 e $0,33 \%$ para as respectivas cultivares, referentes às soluções com 178,$6 ; 143,1$ e $156,4 \mathrm{ppm}$ de $\mathrm{Na}$ fornecido com sulfato, sen- 
do o minimo, para a fonte $\mathrm{NaCl}$, de 0,$28 ; 0,29$ e 0,308 de $\mathrm{N}$ nas soluções com 149,9; 116,2 e 91,9ppm de $\mathrm{Na}$.

Para as cultivares RB70194 e NA56-79 ajustaramse aos teores de fósforo na folha, no tratamento com $\mathrm{Na}_{2} \mathrm{SO}_{4}$ ' regressões lineares, crescente para a primeira com teores variando de $0,28 \%$ atē $0,36 \%$, e decrescente para a segunda com variação de $0,37 \%$ até $0,33 \%$. Para o fornecimento de $\mathrm{NaCl}$ a re gressão que ajustou-se para a RB70194 foi a cūbica, com minimo de $0,27 \%$; inflexão de 0,32\% e mäximo de 0,37\% na presença de 72,$7 ; 154,5$ e 236,2ppm de Na na solução, respectivamente; para a NA56-79 este tratamento provocou efeito quadrático com minimo de 0,28\% de fósforo nas folhas, em solução com 114,4ppm de Na.

Tabela 8. Equaçōes de regressão dos teores de fósforo (y) nas folhas das cinco cultivares $\underline{u}$ tilizadas, em função das fontes e doses de sōdio $(x)$ na soluçào nutritiva.

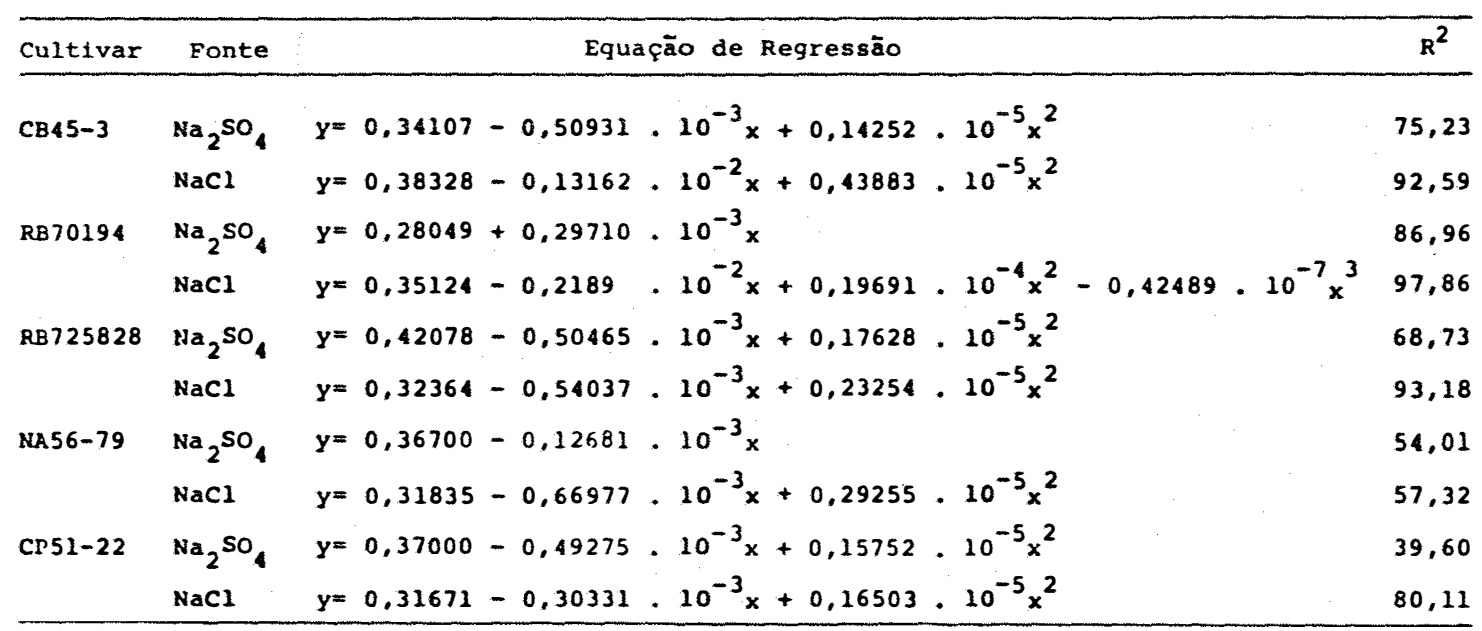

Os resultados estimados mostram que, para a cul 
tivar CB45-3 ambas as fontes de Na afetaram negativamente a concentração de $\mathrm{P}$ nas folhas. Para a 'RB70194' a presença de $\mathrm{Na}_{2} \mathrm{SO}_{4}$ proporcionou incrementos na concentração de $\mathrm{P}$ nas folhas; enquanto que para a fonte NaCl, esta cultivar, apresentou comportamento diferenciado, atē $72,7 \mathrm{ppm}$ de $\mathrm{Na}$ houve decréscimo no teor de $\mathrm{P}$, a partir desta concentração de Na, na solução, o teor de $\mathrm{P}$ elevou-se gradativamente até 236,2ppm de Na quando atingiu valores maiores que os estimados em plantas cul tivadas na solução com omissão de sōdio.

Nas cultivares RB725828, NA56-79 e CP51-22 o em prego de $\mathrm{Na}_{2} \mathrm{SO}_{4}$ causou redução na concentração de $\mathrm{P}$ nas folhas; enquanto que o $\mathrm{NaCl}$ mostrou-se tōxico, conforme regres são quadrātica, atē a concentração média de 107,5ppm de Na, desta concentração em diante observou-se que o teor de $\mathrm{P}$ nas folhas aumentou, atē a dose māxima de Na estudada (276ppm), su perando os teores estimados nas plantas cultivadas em ausência de sōdio.

SYED e EL-SWAIFY (1973) citaram que o fornecimento de sódio na forma de cloreto ou de sulfato, até uma con dutividade de $8 \mathrm{mmhos} / \mathrm{cm}$, não alterou o teor de fósforo na cul tivar NCo310, mas aumentou-o significativamente na H50-7209. O INSTITUT SUGAR RESEARCH (1973), não encontrou correlação en tre os teores de fósforo, nas folhas das cultivares UCW54-65 e HJ5747, cultivadas em diferentes nĩveis de salinidade. 


\subsection{POTฬSSIO}

Os valores mëdios da concentração de potássio nas folhas, em função dos tratamentos, e o resumo da anālise de variância acham-se nas tabelas 9 e 5, e as respectivas equações de regressão na tabela 10.

Tabela 9. Concentração de potássio (\%) nas folhas das diferen tes cultivares de cana-de-açúcar, em função dos tra tamentos: (doses de sódio).

Cultivar

\begin{tabular}{|c|c|c|c|c|}
\hline $0 \mathrm{ppm}$ & 69 ppm & 138 ppm & 207 pren & 276 ppm \\
\hline
\end{tabular}

\begin{tabular}{lllllllllll} 
CB45-3 & 3,12 & 2,75 & 4,15 & 3,25 & 3,75 & 3,36 & 3,39 & 3,02 & 3,19 & 3,29 \\
RB70194 & 3,20 & 2,90 & 3,42 & 3,68 & 3,34 & 3,64 & 2,09 & 3,69 & 1,86 & 4,65 \\
RB725828 & 1,96 & 3,38 & 1,91 & 3,80 & 3,41 & 3,74 & 3,35 & 2,42 & 3,34 & 3,60 \\
NA56-79 & 3,42 & 3,12 & 1,51 & 3,00 & 1,48 & 2,91 & 1,46 & 2,86 & 1,51 & 2,92 \\
CP51-22 & 1,06 & 2,97 & 1,53 & 3,02 & 1,58 & 3,22 & 1,31 & 3,20 & 1,45 & 3,01 \\
\hline
\end{tabular}

Fonte dentro de cultivar e dose 0,38

d.m.s. (Tukey 5\%) Dose dentro de fonte e cultivar 0,54

Cultivar dentro de fonte e dose 0,44

Através dos resultados pode-se observar que hou ve efeito de fonte, dose e cultivar, com interação. Aos teores de potássio nas folhas das cultiva- 
res $\mathrm{CB} 45-3, \mathrm{RB} 70194, \mathrm{RB} 725828$ e NA56-79 ajustaram-se regressões cúbicas, com os seguintes parâmetros:

Cultivar Fonte

Mäximo

Na (ppm)

Na solução ok na solução \&K na solucão ‡K

\begin{tabular}{llllllll} 
CB45-3 & $\mathrm{Na}_{2} \mathrm{SO}_{4}$ & 83,9 & 4,09 & 167,9 & 3,62 & 251,9 & 3,14 \\
& $\mathrm{NaCl}$ & 92,1 & 3,34 & 156,3 & 3,21 & 220,4 & 3,07 \\
RB70194 & $\mathrm{Na}_{2} \mathrm{SO}_{4}$ & 58,7 & 3,60 & 168,8 & 2,71 & 278,9 & 1,81 \\
& $\mathrm{NaCl}$ & 93,3 & 3,71 & 132,8 & 3,65 & 172,3 & 3,60 \\
\multirow{2}{*}{$\mathrm{RB} 725828$} & $\mathrm{Na}_{2} \mathrm{SO}_{4}$ & 223,8 & 3,65 & 118,6 & 2,76 & 13,5 & 1,87 \\
& $\mathrm{NaCl}^{2}$ & 78,8 & 3,83 & 152,9 & 3,63 & 227,0 & 3,43 \\
$\mathrm{NA56-79}$ & $\mathrm{Na}_{2} \mathrm{SO}_{4}$ & 236,4 & 1,63 & 180,4 & 1,46 & 124,5 & 1,30
\end{tabular}

Tabela 10. Equaçōes de regressão dos tecres de potāssio (y) nas folhas das cinco cultivares u tillzadas, em função das fontes e doses de södio $(x)$ na solução nutritiva.

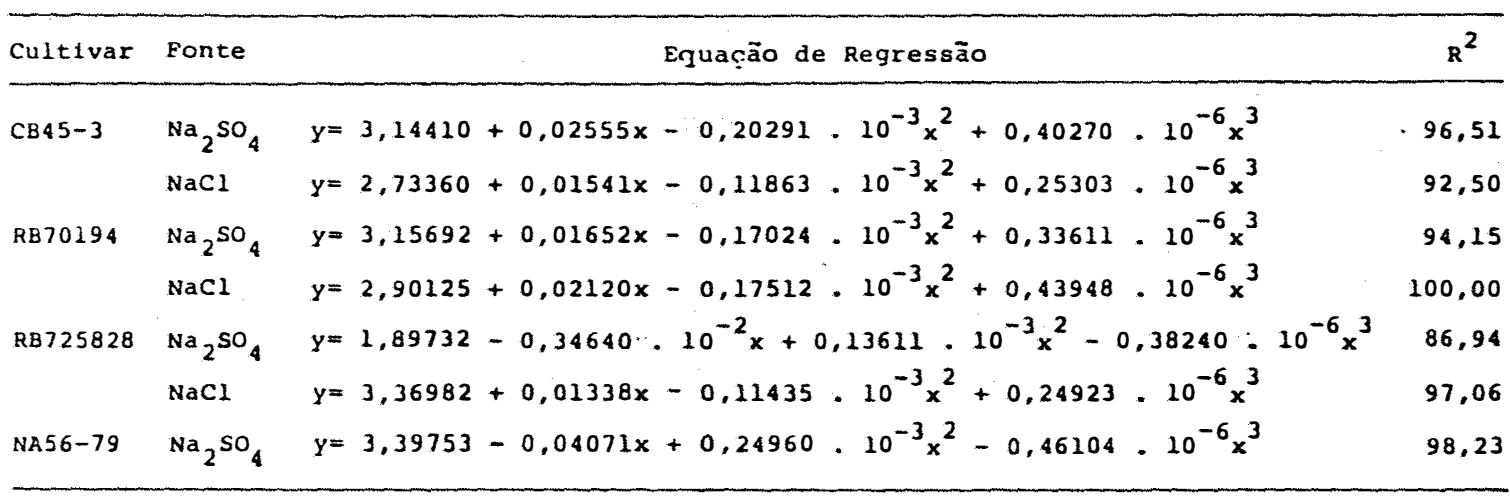

o comportamento das cultivares, quanto a concentração de $\mathrm{K}$ nas folhas, em presença de $\mathrm{Na}_{2} \mathrm{SO}_{4}$, foi bastan- 
te diferenciado, observando-se aumentos, decréscimos e ambos efeitos. Para a cultivar CB45-3 verificou-se acréscimos no te or estimado de $\mathrm{K}$ nas folhas. Na cultivar RB70194 o sulfato de sódio proporcionou efeito duplo, ocorrendo pequeno aumento na concentração de $K$ nas folhas, até a concentração calculada de $58,7 \mathrm{ppm}$ de $\mathrm{Na}$; deste ponto em diante ocorreram acentuados declinios nos teores de K. Para a cultivar RB725828 o efeito do só dio também foi duplo, porém inverso ao observado na 'RB70194', ou seja, pequeno decréscimo na concentração de $K$ nas folhas a té 13,5ppm de $\mathrm{Na}$; e a partir deste ponto o teor de $\mathrm{K}$ elevouse grandemente. O teor de potássio nas folhas da cultivar NA 56-79 foi acentuadamente reduzido na presença das doses de $\mathrm{Na}$ na forma de sulfato.

A fonte $\mathrm{NaCl}$ apresentou efeito mais uniforme, produzindo somente aumentos marcantes, na concentração de potāssio nas folhas das cultivares.

RICHARDS (1973), cita que a elevação da concentração de Na no substrato provoca diminuição no teor de potās sio na planta. Resultados opostos foram encontrados por TYENGAR et alii (1977), pois observaram que o aumento da concentração de $\mathrm{Na}$ na solução nutritiva refletia-se em elevação dos teores de $K$ nas folhas das cultivares Co4l9 e co577.

4.5. CALCIO

Nas tabelas 11, 5 e 12 estão apresentados, os 
resultados médios das concentrações de cālcio nas folhas, o resumo da anālise de variância e as equações de regressão, res pectivamente.

Tabela 11. Concentração de cálcio (\%) nas folhas das diferentes cultivares de cana-de-açūcar, em função dos tratamentos (doses de sódio).

\begin{tabular}{|c|c|c|c|c|c|c|c|c|c|c|}
\hline \multirow[b]{2}{*}{ Cultivar } & \multicolumn{2}{|c|}{0 ppm } & \multicolumn{2}{|c|}{69 ppm } & \multicolumn{2}{|c|}{$138 \mathrm{ppm}$} & \multicolumn{2}{|c|}{207 ppm } & \multicolumn{2}{|c|}{276 ppm } \\
\hline & $\mathrm{Na}_{2} \mathrm{SO}_{4}$ & $\mathrm{NaCl}$ & $\mathrm{Na}_{2} \mathrm{SO}_{4}$ & $\mathrm{NaCl}$ & $\mathrm{Na}_{2} \mathrm{SO}_{4}$ & $\mathrm{NaCl}$ & $\mathrm{Na}_{2} \mathrm{SO}_{4}$ & $\mathrm{NaCl}$ & $\mathrm{Na}_{2} \mathrm{SO}_{4}$ & $\mathrm{NaCl}$ \\
\hline CB45-3 & 0,52 & 0,47 & 0,52 & 0,49 & 0,53 & 0,44 & 0,43 & 0,47 & 0,62 & 0,35 \\
\hline RB70194 & 0,68 & 0,44 & 0,64 & 0,44 & 0,55 & 0,43 & 0,50 & 0,43 & 0,34 & 0,41 \\
\hline RB725828 & 0,51 & 0,39 & 0,64 & 0,42 & 0,75 & 0,36 & 0,54 & 0,46 & 0,71 & 0,38 \\
\hline NA56-79 & 0,58 & 0,54 & 0,45 & 0,40 & 0,42 & 0,38 & 0,37 & 0,28 & 0,50 & 0,33 \\
\hline CP51-22 & 0,52 & 0,54 & 0,47 & 0,43 & 0,42 & 0,48 & 0,33 & 0,45 & 0,35 & 0,42 \\
\hline
\end{tabular}

Fonte dentro de cultivar e dose 0,08

d.m.s. (Tukey 5\%) Dose dentro de fonte e cultivar 0,11

Cultivar dentro de fonte e dose 0,11

Os resultados indicam que houve efeito de fonte, do se e cultivar, com interação.

Ajustaram-se aos teores de cálcio nas folhas das cultivares CB45-3 e RB725828, regressões cưbicas para a fonte $\mathrm{Na}_{2} \mathrm{SO}_{4}$ com mínimo $=0,45$ e 0,59\%; inflexão $=0,50$ e $0,65 \%$ e máximo $=0,56$ e $0,71 \%$, correspondentes às soluções com 189,5 e 
$215,2 \mathrm{ppm}$ de $\mathrm{Na}, 118,6$ e 150,6ppm de $\mathrm{Na}$, e 47,7 e $86,0 \mathrm{ppm}$ de $\mathrm{Na}$. A adição de $\mathrm{NaCl}$ só afetou a concentração de cálcio nas folhas da 'CB45-3', ao qual ajustou-se regressão linear decres cente variando de $0,49 \%$ até $0,39 \%$.

As concentrações de cálcio nas folhas da cultivar RB70194, só foram afetadas pelo sōdio, na forma de $\mathrm{Na}_{2} \mathrm{SO}_{4}$ ' ajustando-se equações de regressões quadrāticas com māximo de $0,68 \%$ de Ca na presença de $47,8 \mathrm{ppm}$ de $\mathrm{Na}$.

A cultivar NA56-79 sofreu efeito quadrātico de ambas: as fontes de sódio, com mínimo de $0,38 \%$ e de $0,31 \%$ de cálcio nas fó lhas correspondentes às soluções com 160,0 e 222,9ppm de $\mathrm{Na}$, fornecidos como sulfato e cloreto, respectivamente.

Observa-se que para a cultivar CP51-22 ajustouse à concentração de Ca nas folhas, regressão linear decrescente para a fonte $\mathrm{Na}_{2} \mathrm{SO}_{4}$, com variação de $0,51 \%$ até $0,37 \%$, e regressão cúbica para a fonte $\mathrm{NaCl}$ com mínimo, inflexão e māximo de 0,$44 ; 0,45$ e $0,47 \%$, correspondentes às soluções com 91,$9 ; 148,4$ e 204,9ppm de Na. (Tabela 12).

A adição de sulfato de sōdio produziu efeito ne gativo sobre a concentração de Ca nas folhas das cultivares RB70194, NA56-79 e CP51-22; e elevação no teor de Ca nas folhas das cultivares CB45-3 e RB725828.

o cloreto de sódio afetou a concentração de Ca nas folhas predominantemente no sentido de diminuir sua concentração. 
Autores, como HAYWARDS e WADLEIGH (1949), FOGIIATA e ASO (1964) revelam que O ion sulfato restringe a absorção do $\mathrm{Ca}$, promovendo a absorção do Na. Os resultados obtidos por SYED e EL-SWAIFY (1973) mostram que tanto o sulfato como o cloreto de sōdio reduziram o conteudo de $\mathrm{Ca}$, nas cultivares NCO310 e H50-7209.

\begin{tabular}{|c|c|c|c|c|}
\hline Cultivar & Eonte & & Equação de Regressāo & $R^{2}$ \\
\hline CB45-3 & $\begin{array}{l}\mathrm{Na}_{2} \mathrm{SO}_{4} \\
\mathrm{NaCl}\end{array}$ & $\begin{array}{l}y=0,51728 \\
y=0,49749\end{array}$ & $\begin{array}{l}+0,19289 \cdot 10^{-2} x-0,25279 \cdot 10^{-4} x^{2}+0,71027 \cdot 10^{-7} x^{3} \\
-0,37318 \cdot 10^{-3} x\end{array}$ & $\begin{array}{l}77,62 \\
58,25\end{array}$ \\
\hline RB70194 & $\mathrm{Na}_{2} \mathrm{SO}_{4}$ & $y=0,67614$ & $-0,30486 \cdot 10^{-3} x-0,31881: 10^{-5} x^{2}$ & 98,12 \\
\hline $\mathrm{RB} 725828$ & $\mathrm{Na}_{2} \mathrm{SO}_{4}$ & $Y=0,49596$ & $+0,56707 \cdot 10^{-2} x-0,46133 \cdot 10^{-4} x^{2}+0,10210 \cdot 10^{-6} x^{3}$ & 68,13 \\
\hline NA56-79 & $\begin{array}{l}\mathrm{Na}_{2} \mathrm{SO}_{4} \\
\mathrm{NaCl}\end{array}$ & $\begin{array}{l}y=0,58849 \\
y=0,54178\end{array}$ & $\begin{array}{l}-0,25217 \cdot 10^{-2} x+0,78764 \cdot 10^{-5} x^{2} \\
-0,20734 \cdot 10^{-2} x+0,46508 \cdot 10^{-5} x^{2}\end{array}$ & 92,51 \\
\hline CP51-22 & $\begin{array}{l}\mathrm{Na}_{2} \mathrm{SO}_{4} \\
\mathrm{NaCl}\end{array}$ & $\begin{array}{l}y=0,51800 \\
y=0,53821\end{array}$ & $\begin{array}{l}-0,69927 \cdot 10^{-3} x \\
-0,25086 \cdot 10^{-2} x+0,19766 \cdot 10^{-4} x^{2}-0,44392 \cdot 10^{-7} x^{3}\end{array}$ & $\begin{array}{l}90,38 \\
86,43\end{array}$ \\
\hline
\end{tabular}

4.6. MAGNESIO

Os teores mēdios de magnēsio nas folhas, em fun ção dos tratamentos, assim como a anālise de variância resumi da e as equações de regressão, encontram-se nas tabelas 13, 5 e 14, respectivamente.

Os resultados revelam que houve efeito de dose e cultivar interagindo com fonte. 
Tabela 13. Concentração de magnésio (\%) nas folhas das diferentes cultivares de cana-de-açūcar, em funçăo dos tratamentos (doses de sódio).

\begin{tabular}{|c|c|c|c|c|c|c|c|c|c|c|}
\hline \multirow{2}{*}{ Cultivar } & \multicolumn{2}{|c|}{0 ppm } & \multicolumn{2}{|c|}{$69 \mathrm{ppm}$} & \multicolumn{2}{|c|}{138 ppm } & \multicolumn{2}{|c|}{207 prom } & \multicolumn{2}{|c|}{276 ppm } \\
\hline & $\mathrm{Na}_{2} \mathrm{SO}_{4}$ & $\mathrm{NaCl}$ & $\mathrm{Na}_{2} \mathrm{SO}_{4}$ & $\mathrm{NaCl}$ & $\mathrm{Na}_{2} \mathrm{SO}_{4}$ & $\mathrm{NaCl}$ & $\mathrm{Na}_{2} \mathrm{SO}_{4}$ & $\mathrm{NaCl}$ & $\mathrm{Na}_{2} \mathrm{SO}_{4}$ & $\mathrm{NaCl}$ \\
\hline CB45-3 & 0,18 & 0,19 & 0,19 & 0,20 & 0,19 & 0,21 & 0,19 & 0,22 & 0,22 & 0,13 \\
\hline RB70194 & 0,23 & 0,19 & 0,24 & 0,22 & 0,21 & 0,18 & 0,21 & 0,20 & 0,18 & 0,14 \\
\hline RB725828 & 0,16 & 0,14 & 0,23 & 0,16 & 0,20 & 0,15 & 0,23 & 0,20 & 0,31 & 0,12 \\
\hline NA56-79 & 0,19 & 0,20 & 0,17 & 0,23 & 0,15 & 0,20 & 0,17 & 0,25 & 0,16 & 0,19 \\
\hline CP51-22 & 0,15 & 0,28 & 0,19 & 0,25 & 0,16 & 0,24 & 0,18 & 0,24 & 0,17 & 0,16 \\
\hline
\end{tabular}

Fonte dentro de cultivar e dose 0,03

d.m.s. (Tukey 5\%) Dose dentro de fonte e cultivar 0,04

Cultivar dentro de fonte e dose 0,04

Nas folhas das cultivares CB45-3 e RB70194 ajustaram-se aos teores de Mg equações lineares, crescente para a primeira, com variação de $0,18 \%$ até $0,21 \%$ e decrescente para a segunda, com variação de $0,24 \%$ até $0,19 \%$, para a fonte $\mathrm{Na}_{2} \mathrm{SO}_{4}$. Houve alteração no comportamento destas cultivares na presença de $\mathrm{NaCl}$, ajustando-se para a $\mathrm{CB} 45-3$ regressão cūbica com pontos de minimo, inflexão e máximo iguais a 0,$18 ; 0,20$ e $0,22 \%$ de Mg correspondentes às soluções com 23,3; 94,3 e 165,3ppm de sódio; para a RB70194 ajustou-se regressão quadrātica com māximo de 0,20\% para solução com $85,2 \mathrm{ppm}$ de $\mathrm{Na}$.

Aos teores de magnésio nas folhas das cultiva- 
res RB725828, e CP51-22 ajustaram-se regressões cúbicas com os seguintes parâmetros:

\begin{tabular}{|c|c|c|c|c|c|c|c|}
\hline \multirow[t]{3}{*}{ Cultivar } & \multirow[t]{3}{*}{ Fonte } & \multicolumn{2}{|c|}{ Máximo } & \multicolumn{2}{|c|}{ Inflexão } & \multicolumn{2}{|c|}{ Minimo } \\
\hline & & $\mathrm{Na}$ (ppm) & & $\mathrm{Na}$ (ppm) & & $\mathrm{Na}$ (ppm) & \\
\hline & & na solução & $8 M g$ & na solução & $\mathrm{gMg}$ & na solução & $\frac{9}{2 M g}$ \\
\hline \multirow[t]{2}{*}{ RB725828 } & $\mathrm{Na}_{2} \mathrm{SO}_{4}$ & 81,2 & 0,22 & 127,2 & 0,21 & 173,3 & 0,20 \\
\hline & $\mathrm{NaCl}$ & 193,2 & 0,19 & 114,7 & 0,16 & 36,4 & 0,13 \\
\hline CP51-22 & $\mathrm{NaCl}$ & 156,2 & 0,25 & 120,9 & 0,24 & 85,6 & 0,23 \\
\hline
\end{tabular}

Para a cultivar NA56-79, aos teores magnésio nas folhas ajustou-se regressão quadrātica, para a fonte $\mathrm{NaCl}$, com máximo de $0,22 \%$ referente à solução com $137,9 \mathrm{ppm}$ de $\mathrm{Na}$.

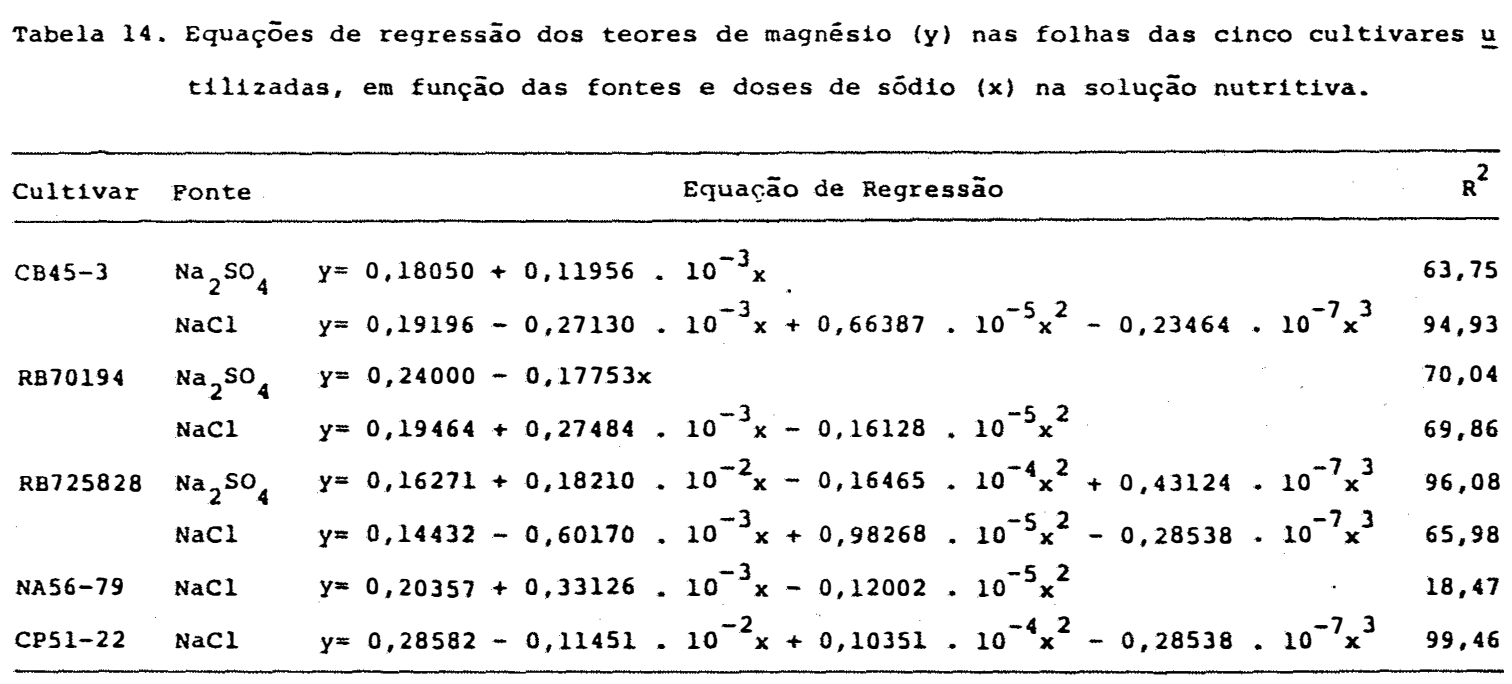


O sulfato de sódio provocou efeitos opostos sobre a concentração estimada de Mg nas folhas das cultivares, elevando-o nas folhas da CB45-3 e RB725828 e decrescendo-o nas folhas da RB70194.

Diferentes respostas das cultivares, em relação ao teor de Mg nas folhas, ocorreram também para a fonte NaCl. As cultivares CB45-3 e RB725828 foram afetadas de maneira a diminuir a concentração de Mg nas folhas, até em média 30 ppm de Na na solução, ocorrendo a partir deste ponto elevação no teor de $\mathrm{Mg}$, até em média $179 \mathrm{ppm}$ de $\mathrm{Na}$, atingindo teores superiores ao encontrado no tratamento com omissão de Na. Para a RB70194 observou-se ligeiro incremento no teor de Mg nas folhas, até $85,2 \mathrm{ppm}$ de $\mathrm{Na}$, desta concentração estimada em diante o $\mathrm{NaCl}$ apresentou efeito depressivo sobre o teor de $\mathrm{Mg}$. A concentração de Mg nas folhas da cultivar NA56-79 apresentouse crescente, beneficiada pelo $\mathrm{NaCl}$; enquanto que nas folhas da cultivar CP51-22 esta fonte afetou negativamente a concentração do nutriente.

SYED e EL-SWAIFY (1973), verificaram que havia acréscimos no conteudo de Mg, nas folhas das cultivares NCo310 e H50-7209, tanto na presença de $\mathrm{Na}_{2} \mathrm{SO}_{4}$ como de $\mathrm{NaCl}$.

\subsection{ENXOFRE}

Os valores médios das concentrações de enxofre 
nas folhas, em função dos tratamentos, o resumo da análise de variância e as equações de regressão encontram-se nas tabelas 15,5 e 16 , respectivamente.

Tabela 15. Concentração de enxofre (\&) nas folhas das diferen tes cultivares de cana-de-açūcar, em função dos trạ tamentos (doses de sódio).

\begin{tabular}{|c|c|c|c|c|c|c|c|c|c|c|}
\hline \multirow{2}{*}{ Cultivar } & \multicolumn{2}{|c|}{0 ppm } & \multirow{2}{*}{$\frac{69}{\mathrm{Na}_{2} \mathrm{SO}_{4}}$} & \multirow{2}{*}{$\frac{\mathrm{ppm}}{\mathrm{NaCl}}$} & 138 & ppom & \multicolumn{2}{|c|}{207 prm } & \multicolumn{2}{|c|}{$276 \mathrm{ppm}$} \\
\hline & $\mathrm{Na}_{2} \mathrm{SO}_{4}$ & 51 & & & $\mathrm{Na}_{2} \mathrm{SO}_{4}$ & $\mathrm{NaC}$ & $\mathrm{Na}_{2} \mathrm{SO}_{4}$ & $\mathrm{~N}$ & $\mathrm{Na}_{2} \mathrm{SO}_{4}$ & 1 \\
\hline CB45-3 & 0,23 & 0,31 & 0,23 & 0,13 & 0,20 & 0,42 & 0,17 & 0,27 & 0,19 & 0,14 \\
\hline RB70194 & 0,21 & 0,33 & 0,22 & 0,58 & 0,23 & 0,48 & 0,22 & 0,30 & 0,17 & 0,2 \\
\hline RB725828 & 0,17 & 0,20 & 0,16 & 0,30 & 0,18 & 0,17 & 0,18 & 0,08 & 0,17 & 0,09 \\
\hline NA56- & 0,20 & 0,19 & 0,21 & 8 & 0,22 & 0,10 & 0,20 & 0,09 & 0,19 & 0,09 \\
\hline CP51-22 & 0,26 & 0,22 & 0,24 & 0,11 & 0,28 & 0,14 & 0,23 & 0,11 & 0,23 & 0,11 \\
\hline
\end{tabular}

Fonte dentro de cultivar e dose 0,06

d.m.s. (Tukey 5\%) Dose dentro de fonte e cultivar 0,09

Cultivar dentro de fonte e dese 0,08

A anălise dos resultados mostra que houve efeito de dose e cultivar, interagindo com fonte.

A concentração de enxofre nas folhas das cultivares só foi afetada pelo tratamento NaCl. Ajustando-se para a CB45-3; RB70194 e RB725828 regressões củbicas com os seguin 
tes parâmetros:

\begin{tabular}{|c|c|c|c|c|c|c|c|}
\hline \multirow{3}{*}{ Cultivar } & \multirow[t]{3}{*}{ Fonte } & \multicolumn{2}{|c|}{ Máximo } & \multicolumn{2}{|c|}{ Inflexão } & \multicolumn{2}{|c|}{ Mínimo } \\
\hline & & $\mathrm{Na}$ (ppm) & & $\mathrm{Na}$ (pprn) & & $\mathrm{Na}$ (ppm) & \\
\hline & & na solução & $8 \mathrm{~S}$ & na solucão & 85 & na solução & 85 \\
\hline CB45-3 & $\mathrm{NaCl}$ & 191,4 & 0,35 & 122,3 & 0,28 & 53,2 & 0,20 \\
\hline 370194 & $\mathrm{NaCl}$ & 76,2 & 0,57 & 163,7 & 0,41 & 251,2 & 0,25 \\
\hline B7725828 & $\mathrm{NaCl}$ & 57,6 & 0,28 & 147,9 & 0,17 & 238,3 & 0,05 \\
\hline
\end{tabular}

Para os teores de $S$ nas folhas da NA56-79 ajustou-se regressão quadrática com mínimo de $0,08 \%$ na presença de 193,5ppm de $\mathrm{Na}$. Enquanto que para a CP51-22 a regressão que ajustou-se aos teores deste elemento foi linear decrescente variando de $0,18 \%$ até 0,098 , respectivamente para "O ppm" e "276 ppm" de Na, na forma de cloreto, na soluçãó.

Tabela 16. Equaçōes de regressão dos teores de enxofre (y) nas folhas das cinco cultivares $\underline{u}$ t1lizadas, em função das fontes e doses de sōdo $(x)$ na solução nutritiva.

\begin{tabular}{lllll}
\hline Cultivar & Eonte & Equação de Regressão & $R^{2}$ \\
\hline CB45-3 & $\mathrm{NaCl}$ & $y=0,29081-0,35062 \cdot 10^{-2} x+0,42120 \cdot 10^{-4} x^{2}-0,11478 \cdot 10^{-6} x^{3}$ & 58,85 \\
RB70194 & $\mathrm{NaCl}$ & $y=0,33785+0,70005 \cdot 10^{-2} x-0,59823 \cdot 10^{-4} x^{2}+0,12176 \cdot 10^{-6} x^{3}$ & 99,98 \\
RB725828 & $\mathrm{NaCl}$ & $y=0,20274+0,32638 \cdot 10^{-2} x-0,35181 \cdot 10^{-4} x^{2}+0,79272 \cdot 10^{-7} x^{3}$ & 98,30 \\
NA56-79 & $\mathrm{NaCl}$ & $y=0,17742-0,97256 \cdot 10^{-3} x+0,25129 \cdot 10^{-5} x^{2}$ & 85,37 \\
CP51-22 & $\mathrm{NaCl}$ & $y=0,18349-0,31159 \cdot 10^{-3} x$ & 54,99 \\
\hline
\end{tabular}


A adição de sódio, na forma de sulfato, não influenciou a concentração de enxofre nas folhas das cultivares.

Na forma de cloreto, o sódio produziu decréscimo no teor estimado de enxofre, nas folhas das cultivares NA56-79 e CP51-22. Nas cultivares RB70194 e RB725828 verificou-se acréscimo no teor de enxofre até $67 \mathrm{ppm}$ de Na, em média; ocorrendo a seguir decréscimos severos naquelas concentrações que atingiram o mínimo na presença, em média, de 244,7 ppm de Na. A cultivar CB45-3 apresentou comportamento oposto ao verificado na 'RB70194' e 'RB725828', ou seja, o efeito de pressivo manifestou-se inicialmente, até $53,2 \mathrm{ppm}$ de $\mathrm{Na}$, para a partir daí ocorrer minimização do efeito tóxico do $\mathrm{NaCl}$, até 191,4ppm de $\mathrm{Na}$, quando o teor estimado de enxofre mostrouse superior ao apresentado pelas folhas das plantas cultivadas em solução com omissão de sódio.

SYED e EL-SWAIFY (1973), citam qque o conteudo de S nas folhas, das cultivares NCo310 e H50-7209, variou sig nificativamente devido ao tipo de sal; ocorrendo aumento no teor de $\mathrm{S}$ na presença de $\mathrm{Na}_{2} \mathrm{SO}_{4}$, e acentuada redução do conte udo de $\mathrm{S}$ quando forneceu-se $\mathrm{NaCl}$, sugerindo a ocorrência de antagonismo entre $\circ \mathrm{Cl}^{-} \mathrm{e} \mathrm{O} \mathrm{SO}_{4}^{-2}$.

4. 8. BORO

As médias da concentração de boro nas folhas das 
cultivares, em função das fontes de sódio, e o resumo da análi se de variância podem ser verificados nas tabelas 17 e 18, e as equações de regressão na tabela 19, respectivamente.

Tabela 17. Concentração de boro (ppm) nas folhas das diferentes cultivares de cana-de-açúcar, em função dos tratamentos. (doses de sódio).

Cultivar

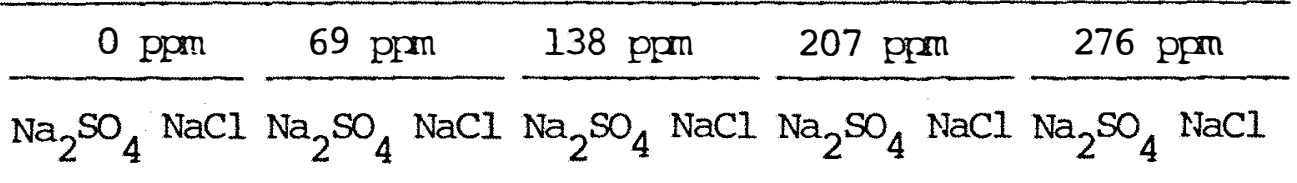

CB45-3

$27,2521,5031,25 \quad 23,5028,25 \quad 26,50 \quad 26,50 \quad 41,25 \quad 26,50 \quad 37,75$

$\mathrm{RB} 70194$ $25,0030,2530,75 \quad 40,5028,75 \quad 35,75 \quad 33,25 \quad 40,00 \quad 27,75 \quad 49,75$

RB725828

$31,00 \quad 18,5027,5042,25 \quad 26,5033,25 \quad 25,75 \quad 29,00 \quad 29,2536,00$

NA56-79

$30,2516,5031,5034,5029,75 \quad 25,5032,75 \quad 26,75 \quad 32,00 \quad 28,00$

CP51-22 $28,25 \quad 13,50 \quad 26,25 \quad 15,75 \quad 25,25 \quad 17,00 \quad 26,75 \quad 17,00 \quad 27,75 \quad 23,25$

Fonte dentro de cultivar e dose 10,59

d.m.s. (tukey 5\%) Dose dentro de fonte e cultivar 15,07

Cultivar dentro de fonte e dose 9,48

Os resultados mostram que houve efeito de dose e cultivar, interagindo com fonte.

Os teores de boro nas folhas sofreram influência somente do $\mathrm{Na}$ fornecido como $\mathrm{NaCl}$. Para as cultivares $\mathrm{CB}$ 45-3, RB70194, RB725828 e NA56-79 ajustaram-se equações cúbi- 


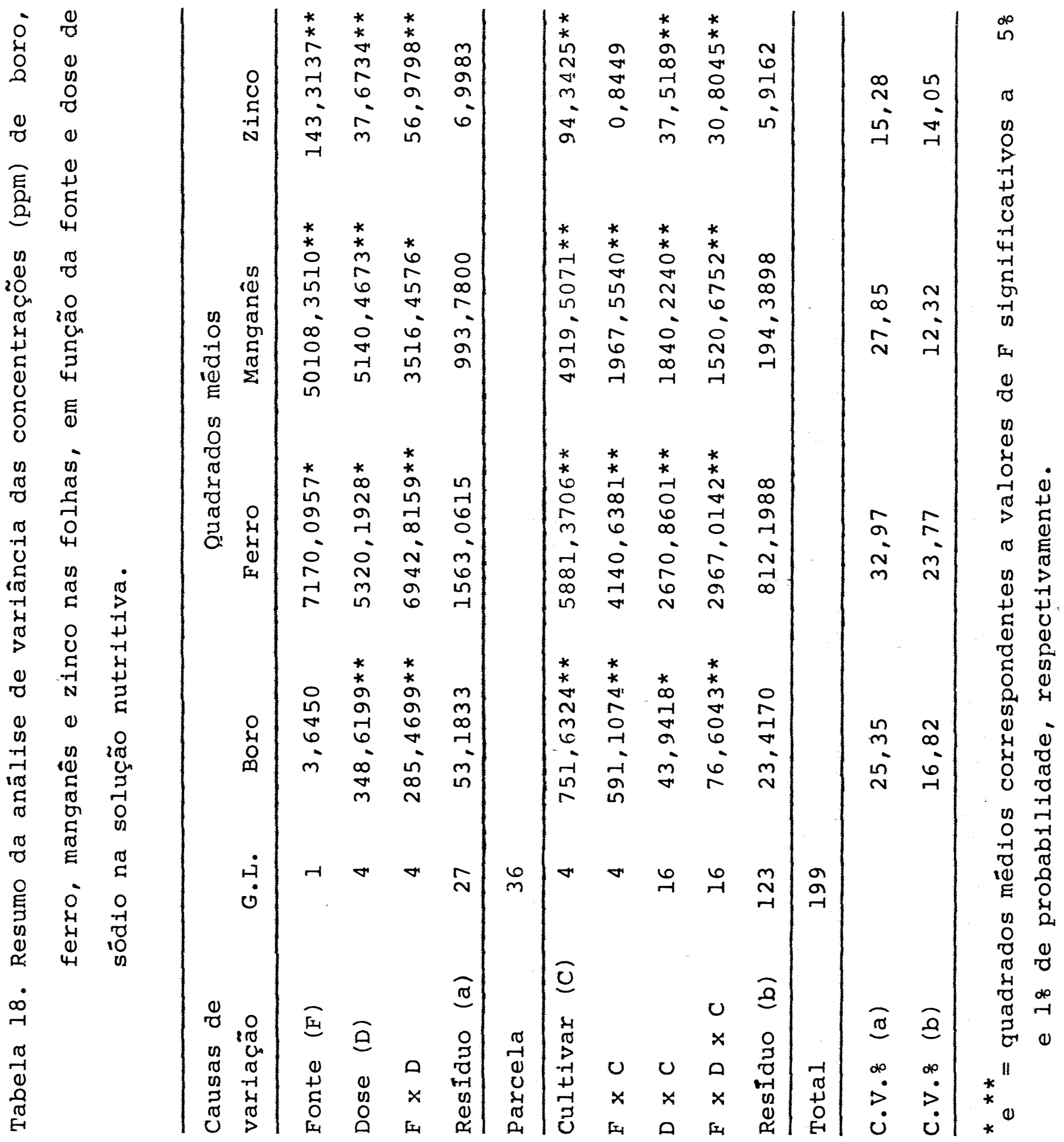


cas com os seguintes parâmetros:

Cultivar Fonte

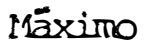

Inflexão

Minimo

$\mathrm{Na}$ (ppm)

$\mathrm{Na}$ (ppm)

$\mathrm{Na}$ (ppm)

na solução ppm B na solução ppm B na solução ppm B

$\begin{array}{lccccccc}\text { CB45-3 } & \text { NaCl } & 240,6 & 40,4 & 138,7 & 30,1 & 36,9 & 19,8 \\ \text { RB70194 } & \text { NaCl } & 86,9 & 39,2 & 130,3 & 38,3 & 173,6 & 37,4 \\ \text { RB725828 } & \mathrm{NaCl} & 83,7 & 40,2 & 151,0 & 33,7 & 218,3 & 27,2 \\ \text { NA56-79 } & \mathrm{NaCl} & 87,1 & 32,3 & 154,9 & 27,9 & 222,8 & 23,7\end{array}$

Na cultivar CP5I-22 ajustou-se, aos teores de boro na folha, equação linear crescente, com mínimo de 13,1 ppm na ausência de sōdio e máximo de 21,4ppm para a última dose.

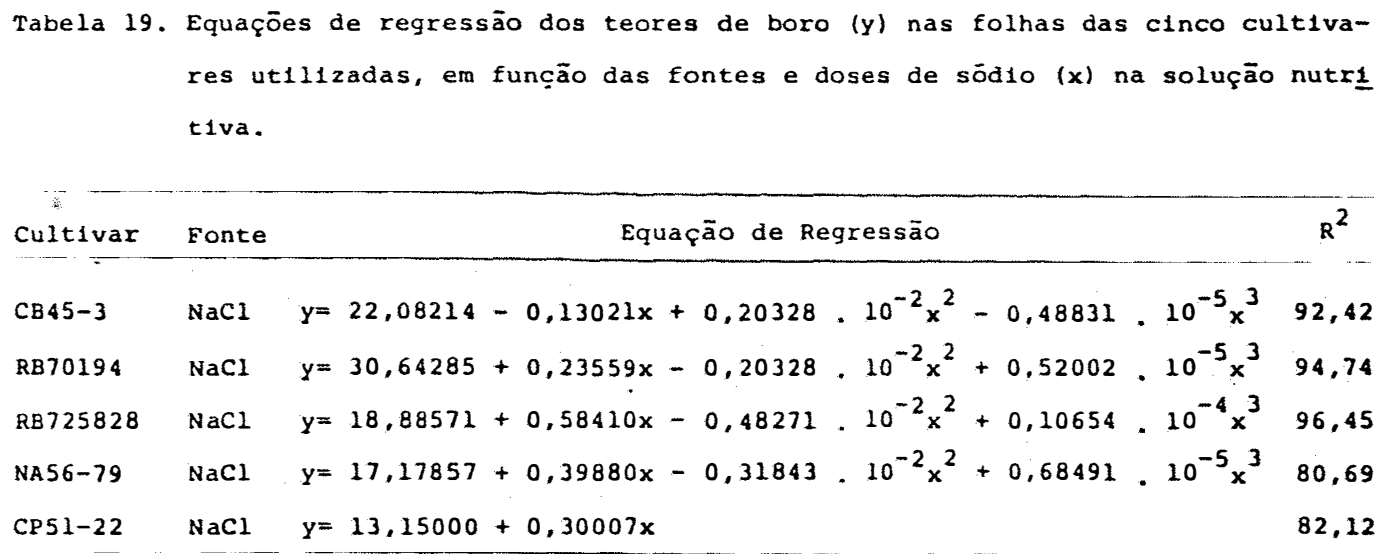

A fonte cloreto de sōdio proporcionou efeito predominante positivo na concentração de boro nas folhas das cul tivares, observando-se leve declinio desta concentração nas 
folhas da CB45-3 quando adiclonou-se atē 36,9ppm de Na, a par tir daí ocorreram aumentos acentuados na concentração de boro mediante a adição de NaCl. Para as cultivares RB70194, RB 725828 e NA56-79 a presença de 85,9ppm de Na, em média, foi a dose que mais elevou a concentração do boro nas folhas, deste ponto em diante verificou-se minimização do efeito positivo do NaCl. Na 'CP51-22' só registraram-se acrēscimos no teor de bo ro, devido incrementos de NaCl na solução.

\section{9. $\mathrm{COBRE}$}

Só foi possível a determinação das concentrações de cobre para a fonte $\mathrm{Na}_{2} \mathrm{SO}_{4}$, as quais são apresentadas na ta bela 20; o resumo da anālise de variância e as equações de re gressão encontram-se nas tabelas 21 e 22 , respectivamente.

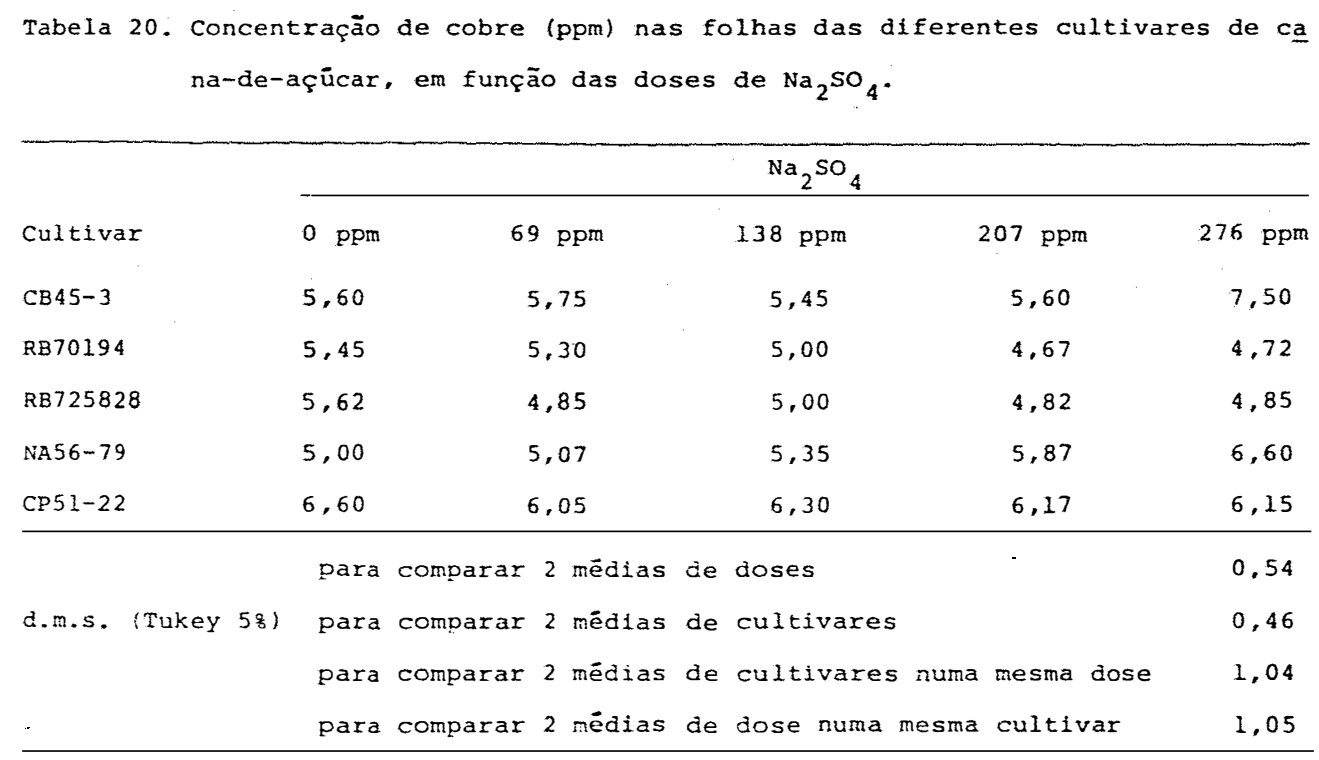


Tabela 21. Resumo da análise de variância das concentrações (ppm) de cobre, em função das doses de $\mathrm{Na}_{2} \mathrm{SO}_{4}{ }^{\circ}$.

Causas de Quadrados médios

variação

G.L. Cobre

Doses (D) 4

$1,1622 *$

Residuo (a)

15

0,3039

Parcela 19

Cultivar

(C)

4

6,1025 **

D $\times C$ 16

1,1635 **

Residuo

(b)

60

0,2709

Total

99
C.V. $\frac{8}{8}$ (a)
9,89
C.V. $\frac{8}{8}$ (b)
9,34

${ }^{*} e^{* *}=$ quadrados médios correspondentes a valores de $F$ signifí cativos a $5 \%$ e $1 \%$ de probabilidade, respectivamente.

Verifica-se que houve efeito de dose e cultivar, com interação.

Aos teores de cobre nas folhas da cultivar $\mathrm{CB}$ 45-3, em presença de $\mathrm{Na}_{2} \mathrm{SO}_{4}$, ajustou-se regressão cúbica; para as cultivares RB70194 e NA56-79, foram ajustadas regressões lineares, com decréscimos de $0,20 \mathrm{ppm}$ de $\mathrm{Cu}$ para incrementos de 69ppm de Na na solução, para a primeira; e acréscimos 0,40ppm 
de cobre para incrementos de 69 ppm de Na na solução, para a segunda.

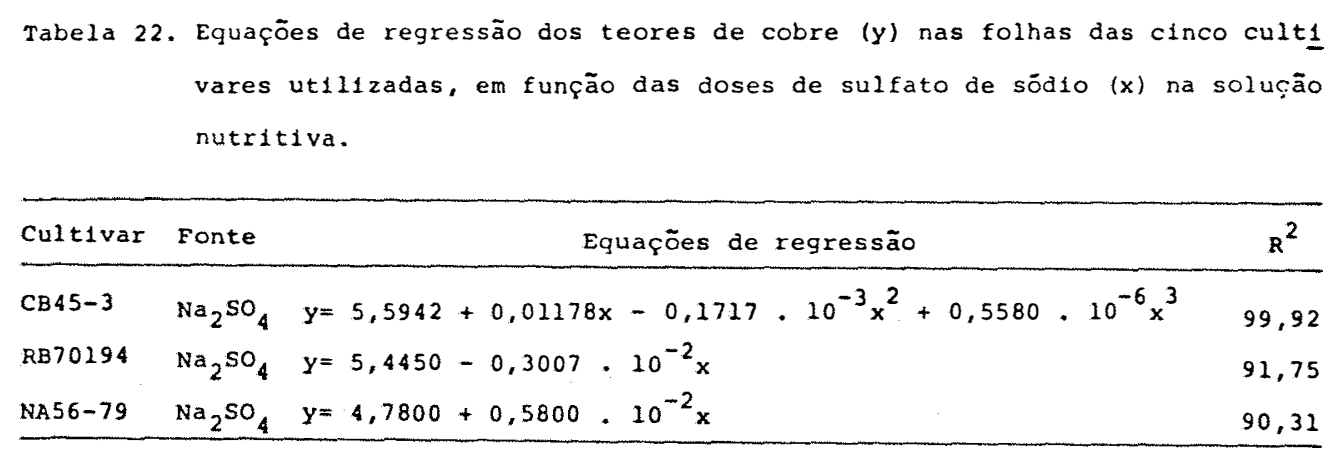

Observa-se que a adição de sulfato de sódio cau sou diferentes efeitos na concentracão de cobre nas folhas das cultivares, na CB45-3 o efeito foi duplo; para a RB70194 só fo ram verificados efeitos depressivos nas concentrações de cobre, enquanto que, na cultivar NA56-79 só ocorreram efeitos po sitivos nos teores deste elemento.

$$
\text { HASSAN et alii (1970 a) e HASSAN et alii (1970 b) }
$$

encontraram correlação negativa entre a aplicação de sulfato de sódio e os teores de cobre, nas folhas de cevada e milho, respectivamente.

4.10. FERRO

Encontram-se nas tabelas 23,18 e 24 as concen- 
trações médias de ferro nas folhas, o resumo da análise de va riância e as equações de regressão, respectivamente.

Tabela 23. Concentração de ferro (ppm) nas folhas das diferen tes cultivares de cana-de-açúcar, em função dos tra tamentos (doses de sódio).

\begin{tabular}{|c|c|c|c|c|c|}
\hline Cultivar & 0 ppm & 69 pppn & 138 ppm & 207 ppm & 276 prm \\
\hline
\end{tabular}

CB45-3 122,5 $101,4 \quad 122,6 \quad 102,8 \quad 114,4 \quad 82,7 \quad 131,2 \quad 83,5 \quad 162,5 \quad 77,3$

RB70194 151,3 106,3 141,5 157,5 121,4 100,4 129,8 111,8 107,4 130,3

RB725828 147,1 $118,9 \quad 123,5 \quad 225,3 \quad 107,5 \quad 95,7 \quad 120,5 \quad 122,8 \quad 117,1 \quad 125,0$

NA56-79 215,5 $130,5 \quad 114,1 \quad 125,2 \quad 94,7 \quad 137,1 \quad 98,0 \quad 107,7 \quad 175,5 \quad 98,2$

CP51-22 $\quad 88,9108,4 \quad 89,1,98,7 \quad 93,7,111,6,85,3,99,2 \quad 174,8,88,6$

Fonte dentro de cultivar e dose 57,42

d.m.s. (Tukey $5 \%$ ) Dose dentro de fonte e cultivar 81,73

Cultivar dentro de fonte e dose 55,85

Verifica-se que houve efelto de fonte, dose e cultivar com interação.

As cultivares CB45-3, NA56-79 e CD51-22 tiveram as concentrações de ferro na folha afetadas somente pela adição de $\mathrm{Na}_{2} \mathrm{SO}_{4}$, ajustando-se para a primeira, equação linear com acréscimos de $9 \mathrm{ppm}$ de Fe para incrementos de 69ppm de $\mathrm{Na}$ 
na solução. Para a segunda, ajustou-se regressão quadrătica com os teores de $\mathrm{Fe}$ decrescendo de $213 \mathrm{ppm}$, nas folhas das plantas cultivadas em ausência de $\mathrm{Na}_{2} \mathrm{SO}_{4}$, para o minimo de $84 \mathrm{ppm}$ na presença de 151 ppm de sódio na solução. Já para a CP51-22, a equação ajustada foi a cübica, com valor māximo de $98 \mathrm{ppm}$ de Fe correspondente a $46 \mathrm{ppm}$ de $\mathrm{Na}$, ponto de inflexão com $89 \mathrm{ppm}$ de Fe correspondente a 103ppm de Na e com mínimo de 81 ppm de Fe correspondente a $159 \mathrm{ppm}$ de $\mathrm{Na}$ na solução.

Nas folhas da RB70194, cultivada em solução com $\mathrm{Na}_{2} \mathrm{SO}_{4}$, aos teores de ferro ajustou-se regressão linear, com decréscimos de loppm de Fe para incrementos de $69 \mathrm{ppm}$ de Na na solução. Este comportamento foi alterado na presença de $\mathrm{NaCl}$, no qual às concentrações de $\mathrm{Fe}$, tanto na 'RB70194' como na RB725828, ajustaram-se regressões cúbicas, com respectivos valores de mínimo, inflexão e māximo de 98 e $87 \mathrm{ppm}, 121$ e 140 ppm, 144 e 193ppm de Fe, correspondentes às soluções com 210 e $221 \mathrm{ppm}, 137$ e 142ppm, 64 e 63ppm de $\mathrm{Na}$.

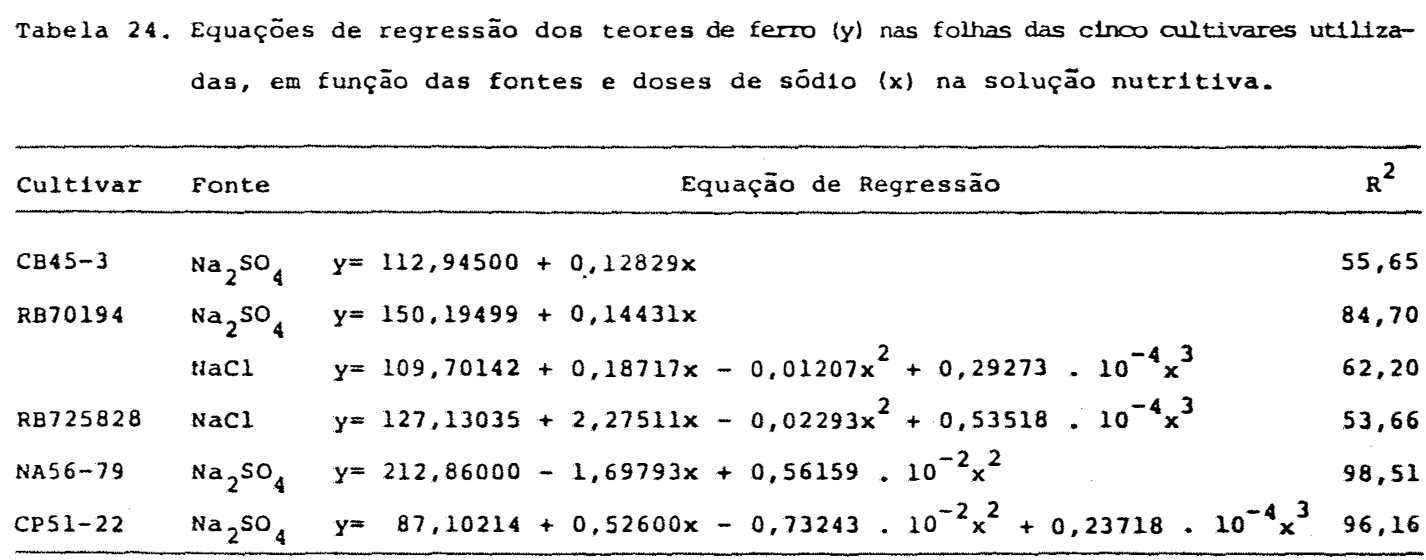


A influência do $\mathrm{Na}_{2} \mathrm{SO}_{4}$ sobre a concentração de ferro nas folhas das cultivares apresentou-se de maneira distinta; enquanto na cultivar $\mathrm{CB} 45-3$ esta fonte de Na acarretou acréscimos lineares; nas cultivares RB70194 e NA56-79 este sal provocou diminuição nos teores deste micronutriente; para a CP51-22 O Na na forma de sulfato acarretou acréscimos no teor de $\mathrm{Fe}$ até $46 \mathrm{ppm}$ de $\mathrm{Na}$, sendo que desse ponto até 159ppm de $\mathrm{Na}$ houve uma pequena redução no teor de $\mathrm{Fe}$, o qual elevou-se acentuadamente a partir dessa concentracão de $\mathrm{Na}$.

As doses de cloreto de sódio provocaram acréscí mos e decréscimos na concentração de $\mathrm{Fe}$, afetando somente as cultivares RB70194 e RB725828, a adição de até 63,5ppm de Na, em média, elevou a concentração estimada de Fe nas folhas, atingindo $168,5 \mathrm{ppm}$. Acima dessa dose verificou-se a ocorrência de efeito depressivo do $\mathrm{NaCl}$, sobre a concentração de $\mathrm{Fe}$, que caiu a 92,5ppm na presença da concentração média de 215,5 ppm de sódio.

HASSAN et alii (1970 a) mostram que os sais $\mathrm{Na}_{2} \mathrm{SO}_{4}, \mathrm{MgSO}_{4}$ e $\mathrm{CaCl}_{2}$ quando presentes no solo proporcionando C.E. de 16mmhos/cm causaram decréscimo na absorção de $\mathrm{Fe}$, em plantas de cevada.

\subsection{MANGANES}

Os valores médios de manganês nas folhas das 
plantas, em função dos tratamentos, a anālise de variância rẹ sumida e as equações de regressão encontram-se nas tabelas 25, 18 e 26 , respectivamente.

Tabela 25. Concentração de manganês (ppm) nas folhas das diferentes cultivares de cana-de-açūcar, em função dos tratamentos. (doses de sódio).

\begin{tabular}{|c|c|c|c|c|c|}
\hline \multirow{2}{*}{ Cultivar } & 0 ppm & 69 ppm & 138 ppm & 207 ppm & 276 ppom \\
\hline & $\mathrm{Na}_{2} \mathrm{SO}_{4} \mathrm{NaCl}$ & $2^{\mathrm{SO}_{4} \mathrm{Na}}$ & $\mathrm{Na}_{2} \mathrm{SO}_{4} \mathrm{NaCl}$ & $\mathrm{Na}_{2} \mathrm{SO}_{4} \mathrm{NaCl}$ & $\mathrm{S}_{2} \mathrm{SO}_{4}$ \\
\hline
\end{tabular}

\begin{tabular}{lllllllllll} 
CB45-3 & 141,1 & 75,4 & 152,4 & 108,5 & 152,5 & 118,5 & 125,2 & 90,7 & 194,3 & 116,3 \\
RB70194 & 159,8 & 57,5 & 164,0 & 100,0 & 151,8 & 106,8 & 103,9 & 78,5 & 80,6 & 108,4 \\
RB725828 & 144,3 & 76,0 & 116,7 & 79,5 & 127,6 & 94,2 & 63,4 & 82,4 & 84,0 & 106,9 \\
NA56-79 & 131,4 & 106,4 & 135,0 & 94,4 & 126,5 & 118,0 & 101,6 & 86,6 & 158,3 & 130,1 \\
CP51-22 & 130,3 & 90,2 & 103,5 & 84,2 & 98,6 & 108,3 & 123,4 & 97,9 & 154,4 & 117,45 \\
\hline
\end{tabular}

Fonte dentro de cultivar e dose 45,78

d.m.s. (Tukey 5\%) Dose dentro de fonte e cultivar 65,17

Cultivar dentro de fonte e dose 27,32

Os resultados mostram efeito de fonte, dose e cultivar com interação.

Foram ajustadas equações cúbicas aos teores de Mn nas folhas da cultivar CB45-3 com mínimo de 131 e $96 \mathrm{ppm}$ pa 
ra soluções com 187 e 215ppm de Na, ponto de inflexão 146 e $106 \mathrm{ppm}$ referentes às soluções com 121 e $151 \mathrm{ppm}$ de Na, máximo de 161 e $116 \mathrm{ppm}$ correspondentes às soluções com 56 e 88ppm de $\mathrm{Na}$, respectivamente para as formas $\mathrm{Na}_{2} \mathrm{SO}_{4}$ e $\mathrm{NaCl}$.

Para a cultivar RB70194, na presença de $\mathrm{Na}_{2} \mathrm{SO}_{4}$ ' ajustou-se regressão quadrātica aos teores de $\mathrm{Mn}$ nas folhas, com máximo de $163 p p m$ correspondente à solução com 21 ppm de Na; regressão cúbica, na presença de $\mathrm{NaCl}$ com mínimo de $83 \mathrm{ppm}$, pon to de inflexão com 95ppm e máximo $107 \mathrm{ppm}$ para as soluções com 213, 150ppm e 88ppm de $\mathrm{Na}$, respectivamente.

Para as cultivares RB725828 e NA56-79, na presença de $\mathrm{Na}_{2} \mathrm{SO}_{4}$ foram ajustadas aos teores de $\mathrm{Mn}$ nas folhas regressões cúbicas respectivamente, com minnimo de 75ppm e 106 ppm, ponto de inflexão 108ppm e $124 \mathrm{ppm}$, e máximo de $141 \mathrm{ppm}$ e $143 \mathrm{ppm}$ correspondentes às soluções com 241 e 192ppm, 128 e 119 $\mathrm{ppm}$ e 16 e $46 \mathrm{ppm}$ de $\mathrm{Na}$, respectivamente. Já para a fonte $\mathrm{NaCl}$, a regressão ajustada para a RB725828 fol linear com acréscí mos de $7 \mathrm{ppm}$ de Mn para incrementos de 69ppm de Na; e quadrátí ca para a NA56-79, com mínimo de 98ppm para solução com 103ppm de $\mathrm{Na}$.

As concentrações de Mn nas folhas da cultivar CP51-22 ajustou-se para a fonte $\mathrm{Na}_{2} \mathrm{SO}_{4}$ regressão quadrática, com mínimo de $100 \mathrm{ppm}$ referente a $115 \mathrm{ppm}$ de Na na solução; e pạ ra a fonte $\mathrm{NaCl}$ ajustou-se regressão linear crescente varian- 
do de $86 \mathrm{ppm}$ de Mn atē $113 \mathrm{ppm}$ de $\mathrm{Mn}$.

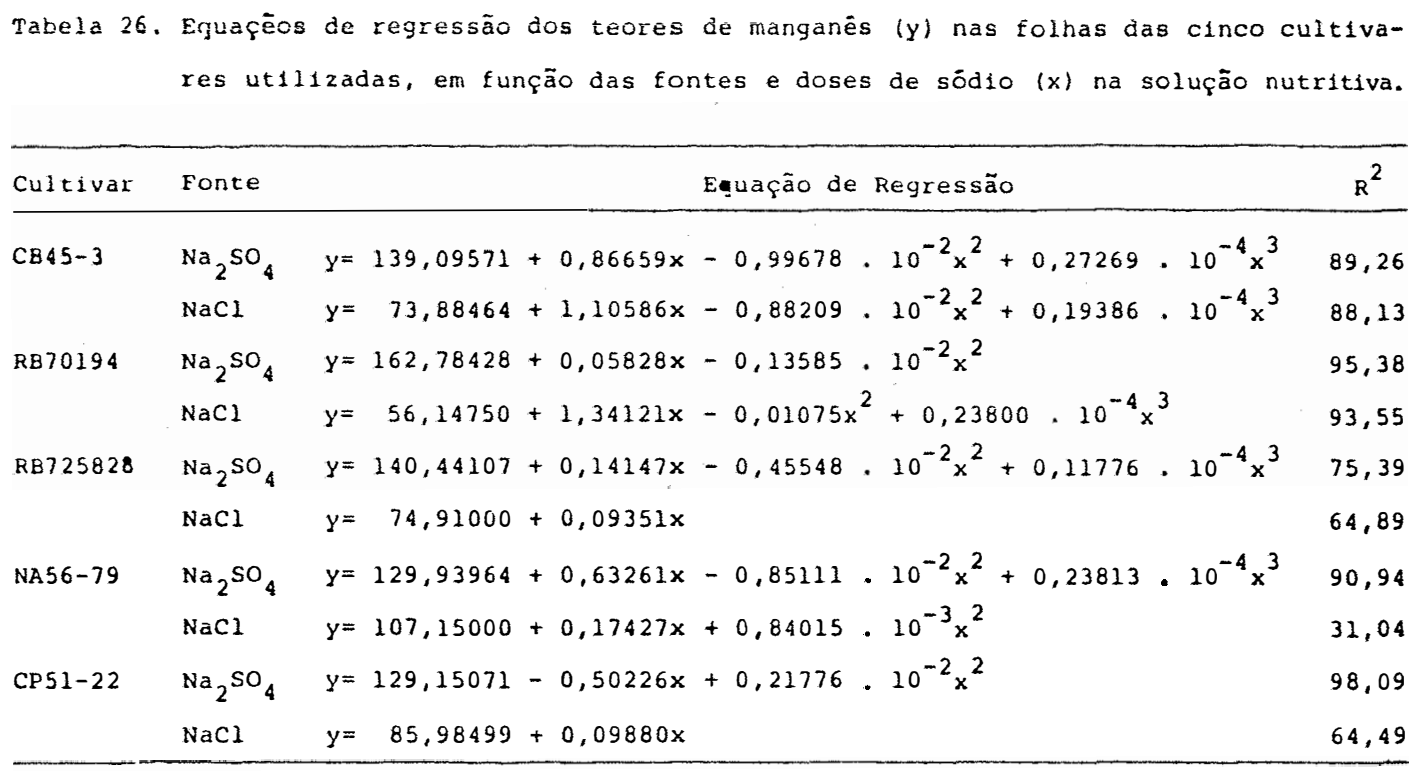

A adição de sulfato de sódio provocou diferentes efeitos nos teores de Mn nas folhas das cultivares, proporcionando decréscimo nos teores do nutriente nas folhas da 'RB 70194' e 'RB725828'; nas cultivares CB45-3 e NA56-79 observouse efeito duplo, o fornecimento de atē $51 \mathrm{ppm}$ de $\mathrm{Na}$, em média, acarretou acréscimos nos teores de $M n$, a partir desta dose es timada atē em média 161,5ppm de Na ocorreram decrēscimos nos teores de Mn, chegando a atingir valores inferiores aos verificados em ausência de sódio, desta concentração em diante re gistraram-se novos incrementos no teor de manganês que ultrapassou as concentrações verificadas anteriormente. Para a CP 
51-22 o fornecimento de até $115 \mathrm{ppm}$ de $\mathrm{Na}$ reduziu o teor deste micronutriente, acima deste ponto estimado o $\mathrm{Na}$ mostrou-se be néfico ao acúmulo de $\mathrm{Mn}$, o qual tornou-se superior ao determinado em ausência de $\mathrm{Na}$.

o cloreto de sódio acarretou uma elevação na con centração estimada de Mn nas folhas das cultivares; para a CB 45-3 e RB70194 as maiores concentrações do nutriente foram re gistradas na presença de $88 \mathrm{ppm}$ de $\mathrm{Na}$, em mẻdia.

HASSAN et alii (1970 b) encontraram decréscimos no acúmulo de manganês, no caule e folhas de milho, quando cul tivado em solos com C.E. de 16 mmhos/cm, induzida por $\mathrm{Na}_{2} \mathrm{SO}_{4}$ ' $\mathrm{MgSO}_{4}$ e $\mathrm{CaCl}_{2}$.

4.12. ZINCO

Os resultados médios dos teores de zinco nas fo lhas, em função dos tratamentos, e a análise de variância resumida encontram-se nas tabelas 27 e 18 , respectivamente, e as equações de regressão na tabela 28 .

Os resultados revelam que houve efeito de fonte, dose e cultivar, com interação. 
Tabela 27. Concentração de zinco (ppm) nas folhas das diferen tes cultivares de cana-de-açūcar, em função dos tra tamentos (doses de sódio).

\begin{tabular}{|c|c|c|c|c|c|}
\hline \multirow{2}{*}{ Cultivar } & 0 ppm & 69 ppm & $138 \mathrm{ppm}$ & $207 \mathrm{ppm}$ & 276 ppsn \\
\hline & $\mathrm{Na}_{2} \mathrm{SO}_{4} \mathrm{Na}$ & $\mathrm{Ja}_{2} \mathrm{SO}_{4} \mathrm{NaCl}$ & $\mathrm{Na}_{2} \mathrm{SO}_{4} \mathrm{NaCl}$ & $\mathrm{Na}_{2} \mathrm{SO}_{4} \mathrm{~N}$ & $\mathrm{Na}_{2} \mathrm{SO}_{4} \mathrm{NaCl}$ \\
\hline
\end{tabular}

CB45-3 $\begin{array}{llllllllllllll}16,05 & 12,60 & 14,35 & 14,20 & 13,15 & 16,17 & 15,75 & 14,07 & 22,17 & 16,52\end{array}$

RB70194 $\begin{array}{lllllllllll}18,25 & 12,40 & 24,60 & 16,77 & 19,90 & 25,67 & 20,90 & 15,67 & 15,50 & 19,15\end{array}$ RB725828

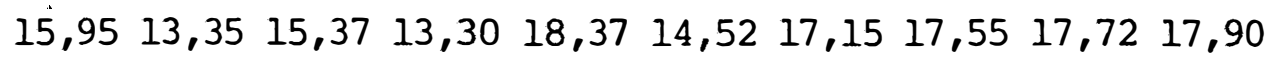
NA56-79 $25,7518,6016,97 \quad 16,62 \quad 16,3722,6018,5013,12 \quad 21,67 \quad 17,97$ CP51-22 $\begin{array}{lllllllllll}17,22 & 19,37 & 19,15 & 14,15 & 17,10 & 18,25 & 15,77 & 15,12 & 20,20 & 15,90\end{array}$

Fonte dentro de cultivar e dose 3,84

d.m.s. (Tukey 5\%) Dose dentro de fonte e cultivar 5,47 Cultivar dentro de fonte e dose 4,76

Os teores de zinco nas folhas das cultivares $C B$ 45-3, RB70194 e NA56-79 sofreram efeito quadrático na presença do tratamento com $\mathrm{Na}_{2} \mathrm{SO}_{4} ;$ a $\mathrm{CB} 45-3$ e NA56-79 com minimo de 13 e $16 \mathrm{ppm}$ de $\mathrm{Zn}$ na presença de 105 e $150 \mathrm{ppm}$ de $\mathrm{Na}$, respectivamente; e a RB70194 com máximo de 22 ppm de $\mathrm{Zn}$ relativo à solução com $113 \mathrm{ppm}$ de $\mathrm{Na}$. Na presença de NaCl ajustou-se aos teores de $\mathrm{Zn}$ nas folhas da CB45-3 regressão linear crescente, de 13 até 16ppm; para a 'RB70194' regressão cúbica com mínimo de 18, pon to de inflexão de 19 e máximo de 2 lppm de $\mathrm{Zn}$, relativos às so 
Iuções com 253, 183 e 114 ppm de $\mathrm{Na}$.

As concentrações de zinco nas folhas da cultivar RB725828 só foram afetadas pelos tratamentos com NaCl, às quais ajustou-se regressão linear crescente, com variação de $12 \mathrm{ppm}$ até $18 \mathrm{ppm}$.

Jã a cultivar CP51-22 apresentou variação nos te ores de zinco nas folhas somente na presença de $\mathrm{Na}_{2} \mathrm{SO}_{4}$, aos quais ajustou-se regressão cūbica com máximo de 19, ponto de inflexão de 17 e minimo de $15 \mathrm{ppm}$, relativos às soluções com 55,126 e $197 \mathrm{ppm}$ de $\mathrm{Na}$.

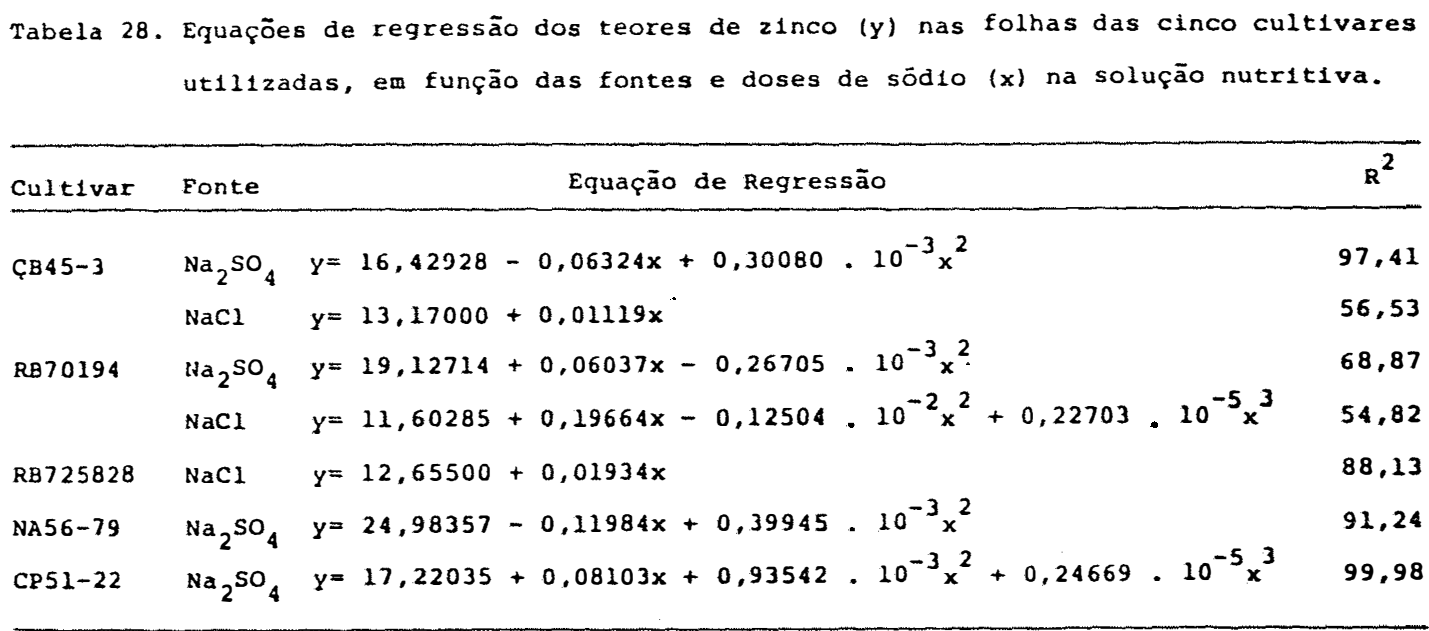

Novamente o sulfato de sódio apresentou-se de ma neira a provocar diferentes comportamentos nas cultivares; a cultivar cB.45-3 apresentou decrēscimo na concentração de zinco até $105 \mathrm{ppm}$ de $\mathrm{Na}$ na solução, sendo que, acima deste ponto houve estímulo na concentração de $\mathrm{Zn}$, que elevou-se acima dos 
teores verificados nas folhas submetidas ao tratamento com omissão de $\mathrm{Na}$.

O $\mathrm{Na}_{2} \mathrm{SO}_{4}$ provocou, na RB70194 elevação no teor de $\mathrm{Zn}$, que atingiu valor māximo de $22 \mathrm{ppm}$, quando empregou-se a dose estimada de $113 \mathrm{ppm}$ de $\mathrm{Na}$; para a cultivar NA56-79 O for necimento de sulfato de sódio provocou decrēscimos nos teores de zinco, minimizados a partir de $150 \mathrm{ppm}$ de $\mathrm{Na}$ na solução. Pa ra a cultivar CP51-22 registrou-se na faixa de concentração, de 0 atē $55 \mathrm{ppm}$ de sódio, na forma de sulfato, aumento no teor de zinco e acima deste ponto estimado, a adição de sulfato de sódio deprimiu o teor do nutriente, até 197ppm de Na, concentração de $\mathrm{Na}_{2} \mathrm{SO}_{4}$ maiores que esta acentuaram a elevação do te or deste micronutriente.

O emprego de $\mathrm{NaCl}$ caracterizou-se por elevar a concentração de zinco nas folhas, das cultivares CB45-3, RB 70194 e RB725828. 
5. CONCLUSÕES

- Ambas as formas, sulfato de sódio e cloreto de sōdio, mostraram-se prejudiciais para o crescimento inicí al das cultivares de cana-de-açúcar: CB45-3, RB70194, RB725828, NA56-79 e CP51-22.

- As cultivares apresentaram, entre si, comportamento diferenciado.

- Não foi possivel avaliar de maneira genérica os efeitos das fontes de sódio, uma vez que, os mesmos foram pro dutos de interações com dosagens e cultivares.

- o sulfato de sódio apresentou em determinadas faixas de concentrações e cultivares, efeitos benéficos sobre a produção de matéria seca e a concentração de nutrientes.

- Independente da forma, sulfato ou cloreto, te ores de sódio, na solução, superiores a $200 \mathrm{ppm}$, em média, afe taram negativamente a acumulação de matéria seca das raỉzes, colmos e folhas.

- Os sais, sulfato e cloreto de sódio, provoca- 
ram nos teores de macro e micronutrientes nas folhas das cultivares, efeitos predominantes no sentido de:

$$
\mathrm{Na}_{2} \mathrm{SO}_{4} \quad \mathrm{NaCl} \quad \mathrm{Na}_{2} \mathrm{SO}_{4} \quad \mathrm{NaCl}
$$

Cultivar

$$
\text { Acréscimos nos teores }
$$

Decréscimos inos teores
$\begin{array}{ll}\text { CB45-3 } & \text { K, Ca } \\ \text { RB70194 N,P }\end{array}$
$\mathrm{K}, \mathrm{Mg}, \mathrm{B}, \mathrm{Mn}, \mathrm{Zn}$
$\mathrm{P}$
$\mathrm{N}, \mathrm{P}, \mathrm{Ca}, \mathrm{S}$
RB725828 N,K,Ca,Mg
$\mathrm{F}, \mathrm{K}, \mathrm{B}, \mathrm{Fe}, \mathrm{Mn}, \mathrm{Zn}$
$\mathrm{K}, \mathrm{Ca}, \mathrm{Mg}, \mathrm{Fe}, \mathrm{Mn}, \mathrm{Zn} \quad \mathrm{Mg}, \mathrm{S}$
NA56-79 in
$\mathrm{P}, \mathrm{K}, \mathrm{Mg}, \mathrm{B}, \mathrm{Fe}, \mathrm{Mn}, \mathrm{Zn} \quad \mathrm{P}, \mathrm{Mn}$
$\mathrm{N}, \mathrm{S}$
CP51-22 N,Fe, I. m, Zn
$\mathrm{P}, \mathrm{Mg}, \mathrm{B}, \mathrm{Mn}$
$\mathrm{P}, \mathrm{K}, \mathrm{Ca}, \mathrm{Fe}, \mathrm{Zn}$
$\mathrm{N}, \mathrm{Ca}, \mathrm{S}$
$\mathrm{P}, \mathrm{B}, \mathrm{Mn}$
$\mathrm{P}, \mathrm{Ca}$
$\mathrm{N}, \mathrm{Ca}, \mathrm{Mg}, \mathrm{S}$ 
6. LITERATURA CITADA

AZEREDO, D. F., 1982. Alumínio no crescimento e na concentração de nutrientes em diferentes cultivares de cana-deaçūcar (Saccharum spp.). Piracicaba, 55p. (Mestrado ESALQ) .

BARNES, A.C., 1964. The Sugar Cane. London, Leonard Hill, $456 \mathrm{p}$.

BARRETO, J.R. e S.V. VALDIVIA, 1979. Influencia de la saliní dad en la producion de la caña de azucar y en las caracteristicas físico-químicas del suelo. Saccharum, Trijilho, $7(2): 89-102$.

BERNSTEIN, L., L.E. FRANGOIS e R.A. CLAKER. 1966. Salt tole rance of NCo varieties of sugar cane. I. Sprouting, growth and yield. Agronomy Journal, Madison, 58(5): 489-493.

BONNET, J.A., 1953. Soil-Salinity studies as related to sugarcane growing in Southwestern Puerto Rico. Journal of Agriculture of the University of Puerto Rico, Puerto Rico, $37(2): 103-113$. 
BONNET, J.A., 1968. Sugar cane problens of saline soils. Su gar y Azúcar, New York, 63 (6):21-23.

EVANS, H., 1959. Elements other than nitrogen, potassium and phosphorus in the mineral nutrition of sugarcane. Proceedings International Society of Sugar Cane Technologists, hㅡ nolulu, $10: 473-508$.

FASIHI, S e H. AHMAD, 1967. Performance of some sugarcane va rieteies under watter-logged and Kallar affected? areas. Agriculture Pakistan, Karachi, 18 (4):457-465.

FOGLIATA, F.A. e P.J. ASO, 1964. Efectos de las sales solubles del suelo sobre el rendimiento sacarino de la caña de azucar. Boletin Estacion Experimental Agricola de la Provincia de Tucuman, no 97, 15p.

HASSAN, N.A.K.; J.V. DREW; D. KNUDSEN e R.A. OLSON, 1970 a. Influence of soil salinity on production of dry matter and uptake and distribuition of nutrients in Barley and corn: I. Barley (Hordeum vulgare L.). Agronomy Journal, Madison , $\underline{62}: 43-45$.

HASSAN, N.A.K.; J.V. DREW; D. KNUDSEN e R.A. OLSON, 1270b。. In fluence of soil salinity on prodution of dry matter and uptake and distribuition of nutrients in Barley and Corn: 
II. Corn (Zea mays L.). Agronomy Journal, Madison, 62 : - $46-48$.

HAYWARD, H.E. e C.H. WALDEIGH, 1949. Plant growth on saline and alkali soils. Advances in Agronomy, New York, 1 : 1-38.

HUMBERT; R.P., 1973. Caña de Azucar: Los problemas de salini dad en su cultivo. Agricultura de las Americas, Kansas, 3 : $14,15,43,44$ e 45 .

IAA-PLANALSUCAR/SUPER., 1980. Relatório Anual. Piracicaba. $116 \mathrm{p}$.

INSTITUT OF SUGAR RESEARCH, 1973. Sal tolerance levels of sugarcane. Annual Report on Industrial Research of the Institute of Sugar Research Departament Jamaica, Kingston, 2932.

IYENGAR, E.R.R.; J.B. PANDYA; B.R. MEHTA, 1977. Effect of sa linity of diluted seawater on two varieties of sugarcane. Salt Research \& Industry, Bhavngar, 13 (1-2): 41-46.

JOSHI, G.V. e G.R. NAIK, 1977. Salinity effect on growth and photosynthetic productivity in sugarcane var. Co740. Indian Sugar, New Delhi, 27 : 329-332. 
JOSHI, G.V. e G.R. NAIK, 1980. Response of sugarcane to different types of salt stress. Pant and Soil, The Haque, $\underline{56}: 255-263$.

KORTSCHACK, H.P., 1975. Salt and $C_{4}$ pathway in sugarcane. Annual Report Hawaiian Sugar Planters Association, Hondulu, 36

LIU, L.J., 1967. Salinity effects on sugarcane germination, growth, and root development. Journal of Agriculture of the University of Puerto Rico, Puerto Rico, 51 : 201-202.

MANNOF, I., 1939. Las aguas salitrosas del rio Sali, su orí gem y sus efectos. Boletin Estação Experimental Agricola de la Provincia de Tucumān, no 29, 17p.

MARETZKI, A; M. THOM e L.G. NICKELL, 1972. Influence of osmotic potentials on the growth and chemical composition of sugarcane cell cultures. Hawaiian Planter's Record, Honolulu, 58 (15): 183-199.

MARTIN, J.P. e F.T. BINGHAN, 1954. Effect of varions exchangeable cations ratios in soils on growth and chemical composition of avocado seedlings. Soil science. New Brunswick, $\underline{78}: 349-360$. 
MASS, E.V. e J.G. HOFFMAN, 1977. Crop salt tolerance-currente assessmet. Journal of the Irrigation and Drainage Divi. sion, ASCE. IR, New York $\underline{2}(103): 115-134$.

MEHRAD, B., 1968. Effect of soil salinity on sugarcane culti vation at Hart Tappeh, Iran. Proceedings International Society of Sugar Cane Technologists, Taipei, 13 : 746-755.

MILLAR, C.E., 1955. Soil Fertility. New York, Jonh Willey; London, Capman \& Hall, 436p.

PIMENTEL GOMES, F., 1977. Curso de Estatistica Experimental. Ed. São Paulo, Nobel, 430p.

POEY, F., 1942. Sales salubles en el suelo dañinas a la caña. In: XVI Congreso de la Associacion de Tecnicos Azu careros de Cuba, Cuba, p. 55-64.

RICHARDS, L.A., 1973. Diagnostico y rehabilitacion de suelos. salinos y sódicos. México, Ed. LIMŨSA, USDA, 169p.

RIZK, T.Y e W.C. NORMAND, 1966: A field study of some effects of salinity on sugarcane. Sugar Bulletin, New Orleans, 44 : 154-155.

RIZK, T.Y. e W.C. NORMAND, 1969. Effects of salinity on Loui 
siana Sugarcane. International Sugar Journal, Manchester, 그 (848): 227-230.

ROBINSON, F.E. e G.F. WORKER, 1965. Growth of sugar cane in areas irrigated with Colorado River water. California Agriculture, Berkeley, 19. (8) : 2-3.

SARRUGE, J.R. e H.P. HAAG, 1974. Análises químicas em plantas. Piracicaba, SP, Escola Superior de Agricultura "Luiz de Queiros", USP, 56p.

SARRUGE, J.R., 1975. Soluções nutritivas. Suma Phitopatholo gica, Piracicaba, 1 : 231-233.

SHEN, I.S. E H.L. TUNG, 1964. Study on salt tolerance in sugarcane. Report of the Taiwan Sugar Experiment Station,' Taipei, $35: 1-24$.

SHOJI, $\mathrm{K}$ e K. SUND, 1965. Drainage and salinity investigation at Halft Tappeh sugar cane project, Iran. Proceedings International Society of Sugar Cane Technologists, San Juan, 12 : 90-95.

SILVA, W.M. da, 1975. Termoterapia em gemas isoladas para controle do raquitismo da soqueira. IN: Anais do III Seminário COPERSUCAR da Agroindustia Açucareira, Aguas de Iin- 
dōia, p. 211-214.

SUND, K. e H. CLEMENTS, 1974. Production of sugarcane under saline desert conditions in Iran. Bulletin of the Hawaii. Agricultural Experiment Station, Honolulu, no 160, 64p.

SYED, M.M. e S.A. EL-SWAIFY, 1972. Effect of saline water ix rigation on NCo310 and H50-7209 cultivars of sugarcane. I. Growth parameters. Tropical Agriculture, Trinidad, 48 (4) : $337-346$.

SYED, M.M. e S.A. EL-SWAIFY, 1973. Effect of saline water ix rigation on NCo310 and H50-7209 cultivars of sugarcane . II. Chemical composition of plants. Tropical Agriculture, Trinidad, $\underline{50}$ (1) : 45-51.

VALDIVIA, S.V. e J. PINNA, 1977. Efecto de la salinidad en el brotamiento de la caña de azucar. Saccharum, Trujilho, 5 (1) : 51-59.

ZERBAN, F.W., 1913. Los sales existentes en las marismas y su relacion con la produccion de caña. Boletin Estacion Expe rimental Agricola de Puerto Rico, n: 4, 44p. 